Required software to e-Annotate PDFs: Adobe Acrobat Professional or Adobe Reader (version 11 or above). (Note that this document uses screenshots from Adobe Reader DC.)

The latest version of Acrobat Reader can be downloaded for free at: http://get.adobe.com/reader/

Once you have Acrobat Reader open on your computer, click on the Comment tab (right-hand panel or under the Tools menu).

This will open up a ribbon panel at the top of the document. Using a tool will place a comment in the right-hand panel. The tools you will use for annotating your proof are shown below:

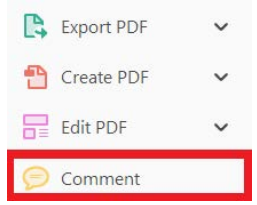

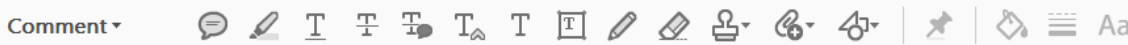

1. Replace (Ins) Tool - for replacing text.

T. Strikes a line through text and opens up a text box where replacement text can be entered.

How to use it:

- Highlight a word or sentence.

- Click on $T_{D}$.

- Type the replacement text into the blue box that appears.

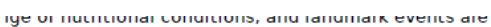
nitored in populations of relatively homogeneous single $\mathrm{n}$ of

and Is initiated atter

carbon source [ 1]. S

are referred to as mei

rof meiosis-specific

inducer of meiosis) [3

I

1 functions as a repre

repression, the genes

pression) and RGRI a।

rase II mediator subur

irectly or indirectly re

Post jstaddon.

Reply $x$

Reply $X$

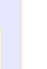


5. Attach File Tool - for inserting large amounts of text or replacement figures.

Inserts an icon linking to the attached file in the Q appropriate place in the text.

How to use it:

- Click on $\&^{\text {- }}$

- Click on the proof to where you'd like the attached file to be linked.

- Select the file to be attached from your computer or network.

- Select the colour and type of icon that will appear in the proof. Click OK.

The attachment appears in the right-hand panel.

:hondrial nreparatior ative da ie extent of membra I, malondialdehyde ( (TBARS) formation.' inad bu biak marfam
6. Add stamp Tool - for approving a proof if no corrections are required.

$\Omega$ Inserts a selected stamp onto an appropriate place in the proof.

How to use it:

- Click on $\Omega$.

- Select the stamp you want to use. (The Approved stamp is usually available directly in the menu that appears. Others are shown under Dynamic, Sign Here, Standard Business).

- Fill in any details and then click on the proof where you'd like the stamp to appear. (Where a proof is to be approved as it is, this would normally be on the first page).

)t the Dusiness cycie, starting with the on perfect competition, constant ret

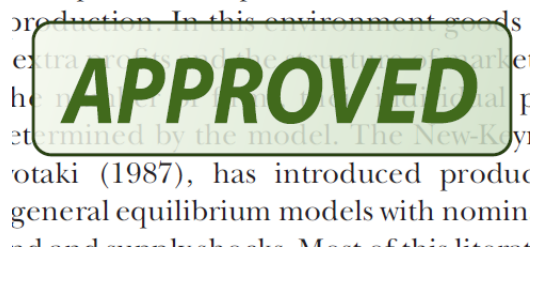

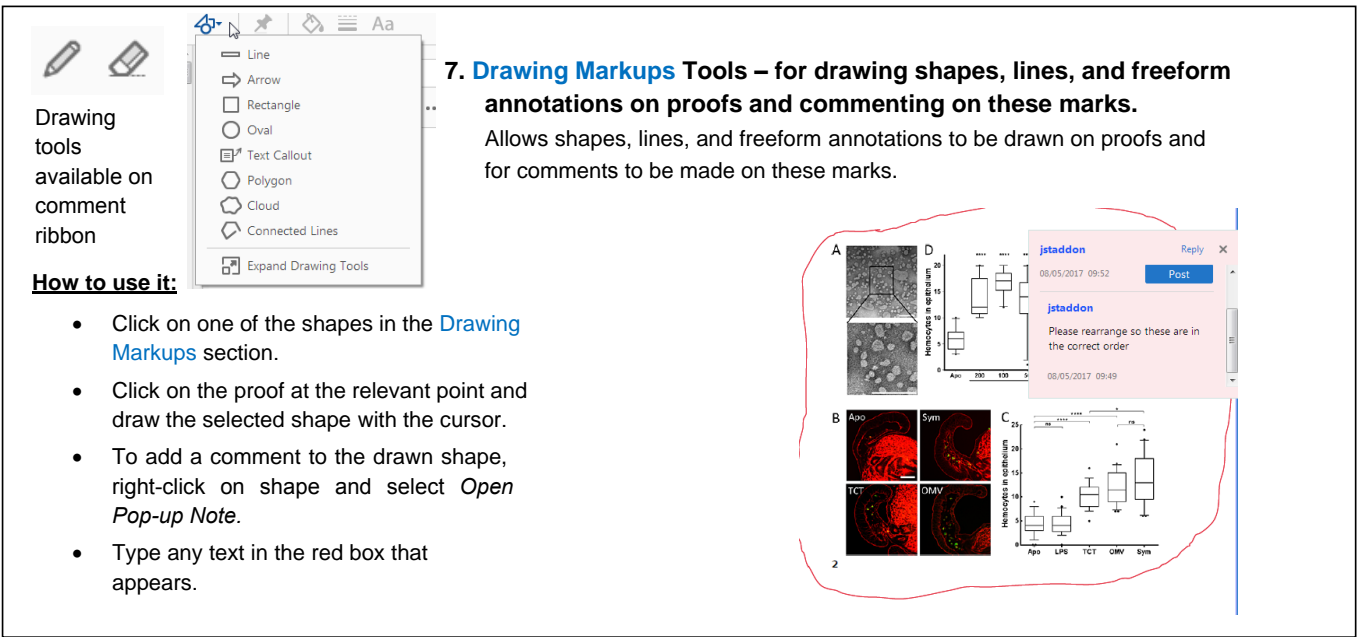

For further information on how to annotate proofs, click on the Help menu to reveal a list of further options:

Welcome...

?) Learn Adobe Acrobat Reader DC..

About Adobe Acrobat Reader DC...

About Adobe Plug-Ins...

Generate System Report...

Repair Installation

Check for Updates... 


\section{Author Query Form}

WILEY

\section{Journal: SPP2}

\section{Article: 1261}

Dear Author,

During the copyediting of your manuscript the following queries arose.

Please refer to the query reference callout numbers in the page proofs and respond to each by marking the necessary comments using the PDF annotation tools.

Please remember illegible or unclear comments and corrections may delay publication.

Many thanks for your assistance.

\begin{tabular}{|l|l|l|}
\hline Query reference & Query & Remarks \\
\hline 1 & $\begin{array}{l}\text { AUTHOR: Please verify that the linked ORCID identifiers are correct for each } \\
\text { author. }\end{array}$ & $\begin{array}{l}\text { AUTHOR: Please confirm that given names (blue) and surnames/family names } \\
\text { (vermilion) have been identified correctly. }\end{array}$ \\
\hline 2 & AUTHOR: Please check that authors and their affiliations are correct. & \\
\hline 3 & AUTHOR: Please check software hyperlinks that have been added. & \\
\hline 5 & AUTHOR: Repetition of Zhang et al.reference? or refers to the species described? & $\begin{array}{l}\text { AUTHOR: In the naming of the new taxon above, you refer to Dr Bach de Roca as } \\
\text { Prof.; please correct one for consistency. }\end{array}$ \\
\hline 6 & $\begin{array}{l}\text { AUTHOR: Sturm and Bach de Roca (1993) has not been cited in the text. Please } \\
\text { indicate where it should be cited; or delete from the Reference List. }\end{array}$ & \\
\hline 7 & &
\end{tabular}




\section{Funding Info Query Form}

Please confirm that the funding sponsor list below was correctly extracted from your article: that it includes all funders and that the text has been matched to the correct FundRef Registry organization names. If a name was not found in the FundRef registry, it may not be the canonical name form, it may be a program name rather than an organization name, or it may be an organization not yet included in FundRef Registry. If you know of another name form or a parent organization name for a "not found" item on this list below, please share that information.

\begin{tabular}{|l|l|}
\hline FundRef name & FundRef Organization Name \\
\hline Spanish Ministry of Economy and Competitiveness & \\
\hline $\begin{array}{l}\text { European Community Research Infrastructure Action } \\
\text { (SYNTHESIS Project) }\end{array}$ & \\
\hline
\end{tabular}




\begin{tabular}{|c|c|c|c|l|l|}
\hline \multirow{2}{*}{$\sim$} & S P P 2 & 1261 & \multirow{3}{*}{ WILEY } & Dispatch: 6.3.19 & CE: Geetha M \\
\cline { 2 - 3 } & Journal Code & Manuscript No. & & No. of pages: 19 & PE: Raymond Appavoo M. \\
\hline
\end{tabular}

[Papers in Palaeontology, 2019, pp. 1-19]

\title{
JUMPING BRISTLETAILS (INSECTA, ARCHAEOGNATHA) FROM THE LOWER CRETACEOUS AMBER OF LEBANON
}

\author{
by ALBA SÁNCHEZ-GARCÍA ${ }^{1}$ (D), ENRIQUE PEÑALVER ${ }^{2}$, XAVIER DELCLÒs ${ }^{1}$ and \\ 2 (1) MICHAEL S. ENGEL ${ }^{3,4}$ \\ ${ }^{1}$ Departament de Dinàmica de la Terra i de l'Oceà \& Institut de Recerca de la Biodiversitat (IRBio), Facultat de Ciències de la Terra, Universitat de Barcelona, \\ Martí i Franquès s/n, 08028, Barcelona, Spain; sanchez.garcia.alba@gmail.com \\ ${ }^{2}$ Museo Geominero, Instituto Geológico y Minero de España, Cirilo Amorós 42, 46004, Valencia, Spain \\ ${ }^{3}$ Division of Invertebrate Zoology, American Museum of Natural History, Central Park West at 79th Street, New York, NY 10024-5192, USA \\ ${ }^{4}$ Division of Entomology, Natural History Museum, \& Department of Ecology \& Evolutionary Biology, University of Kansas, 1501 Crestline Drive, Lawrence, KS \\ 66045-4415, USA
}

Typescript received 14 September 2018; accepted in revised form 4 February 2019

\begin{abstract}
Jumping bristletails (order Archaeognatha), the basalmost order of extant insects, include some of the earliest fossil records among hexapods, yet their overall geological occurrence remains sparse and has provided little insight into their evolution. The earliest representatives of crowngroup bristletails are those in Lebanese amber (Cretaceous), hitherto known only from a single species. Here we significantly expand the known fossil record of Archaeognatha, and from the prolific Lower Cretaceous (Barremian) deposits of Lebanon. One new genus and species, Glaesimeinertellus intermedius gen. et sp. nov., and one new species, Macropsontus bachae sp. nov., are described and figured from
\end{abstract}

Hammana amber, whereas one additional Macropsontus species, M. azari sp. nov., and one meinertellid morphotype are described and figured from Al-Rihan amber. The new taxa are compared with their modern and fossil relatives. Collectively, the new taxa render the Archaeognatha fauna from Lebanese amber the earliest with sufficient preservation to provide character data comparable to modern forms, highlighting the considerable morphological conservatism within the order.

Key words: Hexapoda, Archaeognatha, bristletails, amber, fossils, Cretaceous.
INSECTS have an extensive history that stretches back to, at least, the earliest Devonian, over $410 \mathrm{Ma}$ (Engel \& Grimaldi 2004; Grimaldi \& Engel 2005; Engel 2015). Accordingly, as the most plesiomorphic lineage of living insects, one presumes that the jumping bristletails (Archaeognatha $=$ Microcoryphia) are similarly archaic. Historically, Archaeognatha were grouped with the silverfish (Zygentoma) in the order Thysanura, which contained those families of primitively wingless insects (Remington 1954, 1955). This assemblage was at times enlarged as the Apterygota, which also included the orders of non-insect hexapods (i.e. the Entognatha: Diplura, Protura and Collembola) (Börner 1904; Verhoeff 1905). Abundant phylogenetic evidence reveals that apterygotes are an unnatural grouping, and that even the Thysanura are paraphyletic (Hennig 1969, 1981). Unlike the Zygentoma, Archaeognatha retain a long, slender, monocondylar mandible and lack a gonangulum at the base of the ovipositor. These features not only help to distinguish the two orders but also reveal the affinity of the former group to the winged insects, or Pterygota (Hennig 1969, 1981; Mendes 2002; Grimaldi \& Engel 2005; Engel et al. 2013). The separation of bristletails and silverfish into two orders is today universally accepted, the 'thysanurans' forming a grade to the pterygotes.

There is much about bristletails that is plesiomorphic, such as the primitive absence of wings, presence of three terminal filaments (two cerci and a median caudal filament), monocondylar mandibles, and lack of a gonangulum. Species range in length from 6 to $20 \mathrm{~mm}$ and have an overall cylindrical habitus, with the second and third thoracic nota hunched in profile. Archaeognatha are generally defined by a slew of anatomical traits: integument generally covered with scales, typically arranged in distinctive patterns; large and contiguous compound eyes, and three well-developed ocelli (the two last traits putatively owing to their nocturnal habits); long, flagellate antennae; long maxillary palpi, with seven palpomeres; head skeleton composed of paired anterior and posterior sclerotic plates; meso- and metapleura consisting of a 
single sclerite, with large pleural apodemes; legs with coxal styli on meso- and metacoxae, on metacoxae only or completely absent; tarsi with two or three rigidly united tarsomeres; pretarsi with paired claws and lacking empodia; abdominal coxosternites with styli and eversible vesicles; and the aforementioned, three posteriorly directed caudal filaments (Sturm \& Machida 2001; Grimaldi \& Engel 2005). Bristletails are also distinctive for their particular jumping mechanism which is the result of a sudden flexion of the abdomen that propels the insect into the air and is partially made possible by the arched thoracic segments. Species occur in a wide variety of climates, from the tropical rain forest, living on the forest litter around the bases of living or fallen trees, to the rocky areas of dry regions, where they are principally petrophilous and live in stone crevices (Mendes 1990). Many bristletails feed on green algae, lichens and detritus of decaying leaves (Sturm \& Machida 2001). Sturm \& Machida (2001) and Mendes (1990, 2002) have provided general overviews regarding the biology and systematics of Archaeognatha. Extant Archaeognatha consist of about 500 species in two families - the putatively more plesiomorphic Machilidae (itself organized into the subfamilies Machilinae, Petrobiinae and Petrobiellinae), and the more derived Meinertellidae (Sturm \& Machida 2001). The former family is mostly distributed in the Northern Hemisphere, with few exceptions in Africa and Asia, while the latter is principally found in the Southern Hemisphere (Sturm \& Machida 2001; Mendes 2002).

Unfortunately, the fossil record of Archaeognatha is sparse. Fragments of cuticle from the mid-Devonian of Gilboa, New York, USA, may represent an early bristletail (Shear et al. 1984), while a head and thorax of a definitive bristletail recovered from fissures in the Gaspé fossil beds of Quebec, Canada, may represent a more recent contaminant rather than a later Devonian record of the order (Labandeira et al. 1988; Jeram et al. 1990). Unfortunately, these fragments provide little information on the Devonian record of Archaeognatha. Several Carboniferous and Permian species placed in the extinct family Dasyleptidae are apparently stem-group Archaeognatha, recognized earlier as the Monura and sometimes as an order or suborder (Sharov 1957; Kukalová-Peck 1987, 1991, 1997). These fossils are larger than most modern Archaeognatha and appear to be represented by juveniles, frequently shed exuviae (Bitsch \& Nel 1999; Rasnitsyn 1999; Grimaldi 2001; Rasnitsyn et al. 2004; Engel 2009). Bechly \& Stockar (2011) described a fossil species from the mid-Triassic of Meride Limestone of Monte San Giorgio, Switzerland as a dasyleptid, and considered the family to be a plesiomorphic suborder, sister to all Recent bristletails. An earlier Triassic fossil, Triassomachilis uralensis Sharov, was originally described as an archaeognathan (Sharov 1948), but its identity has been questioned (Bitsch 1994; Grimaldi \& Engel 2005), with several authors regarding it as a nymphal mayfly (Bitsch \& Nel 1999; Sinitshenkova 2000; Bechly \& Stockar 2011). Aside from body fossils, various trace fossils have been described putatively representing the movement of dasyleptids across various substrates (Benner et al. 2015).

Apart from dasyleptids and the controversial fossils, the record of Archaeognatha is almost entirely restricted to several Cretaceous and Cenozoic ambers, and to the extant families Machilidae and Meinertellidae. The oldest Mesozoic meinertellid described and unquestionably placed in the Machiloidea is an individual of Cretaceomachilis libanensis Sturm and Poinar from the Lower Cretaceous amber of Lebanon (Sturm \& Poinar 1998). Further Cretaceous amber Archaeonatha are known from the Albian of Spain (Peñalver \& Delclòs 2010), Cenomanian of Myanmar (Burma) (Grimaldi et al. 2002; Mendes \& Wunderlich 2013; Zhang et al. 2018), and Turonian of New Jersey (Grimaldi et al. 2000; Sturm \& Machida 2001), although only a fraction of these have been thoroughly documented. The Cenozoic record is not much better, where jumping bristletails are described exclusively in amber, and from the Eocene of the Baltic region (Koch \& Berendt 1854; Gadeau de Kerville 1893; Olfers 1907; Silvestri 1912; Haug et al. 2015), the Miocene of Mexico (Wygodzinsky 1971; Riquelme et al. 2015), and the Miocene of the Dominican Republic (Sturm \& Poinar 1997). There is also a published record of a meinertellid from Venezuelan copal (Mendes 1997a). Zygentoma have a similarly sparse fossil record that is analogous richest during the Cenozoic and Cretaceous, although hitherto silverfish are known from Burmese, Baltic, Mexican and Dominican ambers (Silvestri 1912; Mendes 1997b, 1998; Sturm \& Mendes 1998; Mendes \& Poinar 2004, 2008, 2013; Mendes \& Wunderlich 2013).

Although a single species has previously been described from the amber of Lebanon (Sturm \& Poinar 1998), there is additional Lebanese material from a variety of different deposits and spanning the Barremian (Al-Rihan and Hammana outcrops). Although not abundant, this material provides new morphotypes and collectively represents the earliest fauna of Archaeognatha with sufficient preservation as to obtain character data comparable to modern forms. We therefore provide here an account of this diversity, aiming to build a body of data to allow future interpretations on the Cretaceous evolution of the Archaeognatha.

\section{MATERIAL AND METHOD}

\section{Locality and stratigraphy}

Lebanese amber represents one of the most important fossil Konservat-Lagerstätten from which to learn about 
life during the Early Cretaceous, and it remains as the earliest fossiliferous resin providing abundant biological inclusions (Azar 2007; Azar et al. 2010). Amber has been recorded from more than 450 fossil localities throughout Lebanon and spanning from the Late Jurassic (Kimmeridgian) to the Early Cretaceous (Albian) in age (Maksoud et al. 2017), although only the Barremian outcrops have yielded arthropods, mostly insects, as bioinclusions (Azar et al. 2010). The Lower Cretaceous amber-bearing outcrops are found in three intervals at the upper part of the 'Grès du Liban' (Sandstone of Lebanon); the middle and upper intervals recently dated as early and late Barremian, respectively, and the lower interval dated as early Barremian or possibly older. Nevertheless, it has been noted that amber pieces with inclusions from the middle and upper intervals could be reworked from the lower interval (Maksoud et al. 2017). The present amber pieces originate from two outcrops: Hammana (belonging to the upper interval) and AlRihan (belonging to the lower interval), together these have yielded most of the known Lebanese arthropod inclusions (Azar et al. 2010). Based on geological and palaeontological data, these deposits correspond to siliciclastic coastal and estuarine environments, where amber is always associated with levels of dark shales with lignite and other fossil plant remains from the three intervals (Maksoud et al. 2014, 2017; Granier et al. 2015). The localities have been recently mapped by Maksoud et al. (2014, 2017) (Fig. 1).

Specimens 1222 and 1565 (Figs 2-7) were found at the outcrop of Hammana, Baabda District, Mount Lebanon Governorate, in central Lebanon, which has yielded thousands of arthropod inclusions of about 20 different orders (Azar et al. 2010). Specimens RIH-2A and RIH-4A (Figs 8-10) were found at the outcrop of Al-Rihan, Jezzine Department, South Lebanon Governorate, in southern Lebanon, and where c. 40 inclusions have been discovered to date. The Al-Rihan outcrop has so far yielded the specimens of Archaeognatha reported herein as well as arthropod inclusions of the following clades: Acariformes, Araneae, Orthoptera, Blattaria, Mantodea, Psocoptera, Thysanoptera, Hemiptera, Hymenoptera, Neuroptera, Coleoptera and Diptera (Azar \& Nel 2013; Delclòs et al. 2016).
FIG. 1. Map of Lebanon with locations of the Lower Cretaceous amber outcrops. Modified after Maksoud et al. (2017). Grey areas indicate the distribution of the amber localities. Black circles indicate the outcrops with fossil inclusions, and stars those outcrops preserving Archaeognatha studied in this paper. Scale bar represents $10 \mathrm{~km}$.

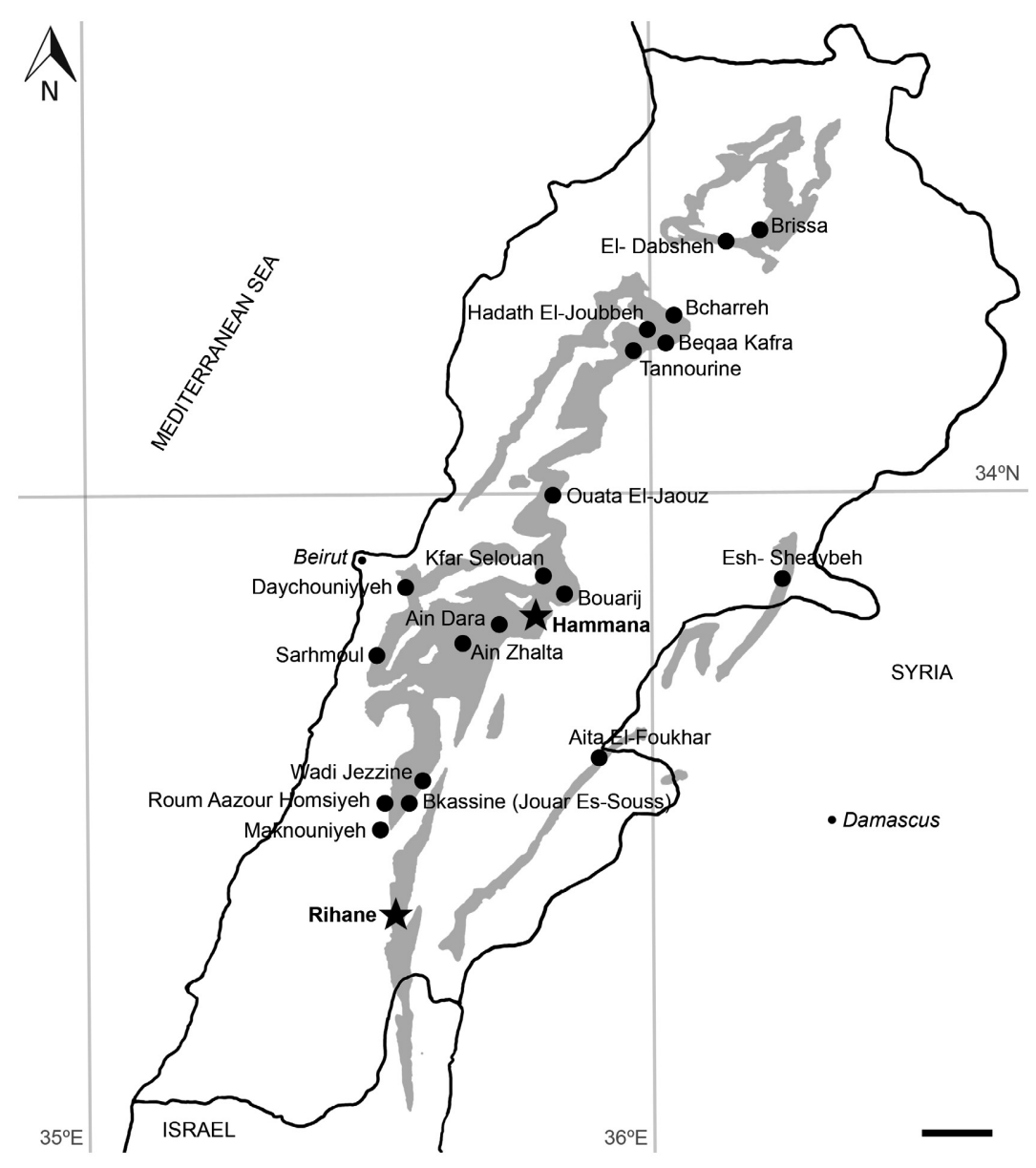


Preparation and descriptive method

Lebanese amber is highly mature and fractures easily, so the amber pieces containing the inclusions were stabilized in a medium of Canada balsam and then mounted between glass coverslips (Azar et al. 2003). The individual fossils were examined with Nikon SMZ 1500 and Olympus SZX12 stereomicroscopes and a BX41 compound microscope using reflected and transmitted light. Measurements were taken using ImageJ software (https://imagej.nih.gov/ ij) and recorded in millimetres. Microphotography was performed with an AmScope MU900 digital camera attached to a Nikon SMZ 1500 stereomicroscope with AmS-

4 cope ToupView 3.5 software (http://www.touptek.com), at the Muséum national d'Histoire naturelle (Paris, France), and a Moticam 2500 digital camera attached to a Motic BA310 compound microscope with Motic Images Plus 2.0 software (https://www.motic.com/As_Support_Download), at the Universitat de Barcelona (Barcelona, Spain). Helicon Focus software was used to combine photographs of a given inclusion at different focal depths (https://www.heliconsof t.com/heliconsoft-products/helicon-focus). Camera lucida drawings were prepared with a drawing tube attached to an Olympus CX41 compound microscope at the Universitat de Barcelona. The images were arranged in Adobe Photoshop CS3.

Morphological terminology used throughout is namely that widely employed in the systematics of Archaeognatha (Sturm \& Machida 2001), although in the descriptions we have abbreviated the specific palpomeres of the maxillary and labial palpi as ' $\mathrm{P}_{n}$ ', where $n$ refers to a specific palpomere as numbered from base to apex (e.g. $\mathrm{P}_{3}$ would indicate the third palpomere). All of the material reported herein is deposited in the amber collection of the Natural History Museum of the Lebanese University, Faculty of Sciences II, Fanar, Lebanon.

\section{SYSTEMATIC PALAEONTOLOGY}

\author{
Order ARCHAEOGNATHA Börner, 1904 \\ Family MEINERTELLIDAE Verhoeff, 1910
}

\section{Genus GLAESIMEINERTELLUS nov.}

LSID. urn:lsid:zoobank.org:act:854FC159-20A4-4DBE-9753ED0A02EB6569

Derivation of name. The generic name is a combination of the Latin glaesum (meaning, 'amber'), and Meinertellus Silvestri, type genus of the family. The gender of the name is masculine.

Type species. Glaesimeinertellus intermedius sp. nov.
Diagnosis (female). Maxillary $\mathrm{P}_{2}$ without a hook-like process; labial $\mathrm{P}_{2}$ without a protrusion; labial $\mathrm{P}_{3}$ slightly widened distally, with numerous sensilla basiconica (type D: Sturm \& Machida 2001); compound eyes large and rounded; frons slightly protruding; profemora not wider than meso- and metafemora; only hindleg with coxal styli; spiniform setae present on legs; tarsi trimerous, without scopula; apical spine of abdominal styli thin and long.

\section{Glaesimeinertellus intermedius sp. nov.}

Figures 2-4

LSID. urn:lsid:zoobank.org:act:FB36EFDC-C236-41DA-B1293233C46FEB83

Derivation of name. The specific epithet is derived from the Latin intermedius, meaning, 'in the middle', and in reference to the mixture of primitive and derived characters of the species.

Type specimen. 1222 (coll. Azar), holotype; juvenile or sub-adult specimen, female; partially preserved and observable dorsally and ventrally; the cuticle is highly damaged, but details of the antennae (incomplete), maxillary palpi, labial palpi, legs and abdominal styli are visible; preserved in a thin section of transparent yellow amber together with several loose fragments of a flagellum in close association; no syninclusions.

Diagnosis. As for genus (see above).

Description. Female. Body (Figs 2, 3) length as preserved $3.97 \mathrm{~mm}$ (without appendages), covered with scales (scale pattern indiscernible). Appendages (antennae, maxillary and labial palpi, legs, and styli) devoid of scales.

Head (Fig. 4A) orthognathous; frons slightly protruding, with few short setae; posterodorsal surface of head partly preserved. Compound eyes partly preserved, large, flattened, round-shaped, holoptic (i.e. in contact along median tangent), and composed of many ommatidia (average diameter of ommatidia $0.02 \mathrm{~mm}$ ); exact ocular ratios (length/width of compound eye, and length of contact line/length of compound eye) not measurable due to nature of preservation, but length of contact line almost reaching entire length of compound eyes. Ocelli not accessible. Antenna (Fig. 3) incomplete, length as preserved $3.14 \mathrm{~mm}$; scape robust, length $0.26 \mathrm{~mm}$, width $0.14 \mathrm{~mm}$; pedicel length $0.10 \mathrm{~mm}$, width $0.10 \mathrm{~mm}$; flagellum subdivided into numerous elements, with distinct breakpoints (with a narrowed diameter and lack of setae: Fröhlich \& Lu 2013) separated by 7-8 flagellomeres; each flagellomere bearing one or two whorls of long, slender, curved, acuminate setae. Maxillary palpus (Fig. 4A) 7-segmented, fairly stout, with abundant, simple setae; $\mathrm{P}_{1}$ with a pronounced triangular process dorsally; $\mathrm{P}_{2}$ without a hook-like process; $\mathrm{P}_{7}$ conical, distinctly shorter than $\mathrm{P}_{6}\left(\mathrm{P}_{7} / \mathrm{P}_{6}\right.$ length ratio $\left.(0.07 / 0.17) 0.41\right)$, although measurements possibly underestimated due to foreshortened position; $\mathrm{P}_{5}$ without spines; $\mathrm{P}_{6}$ and $\mathrm{P}_{7}$ with dorsal hyaline spines 


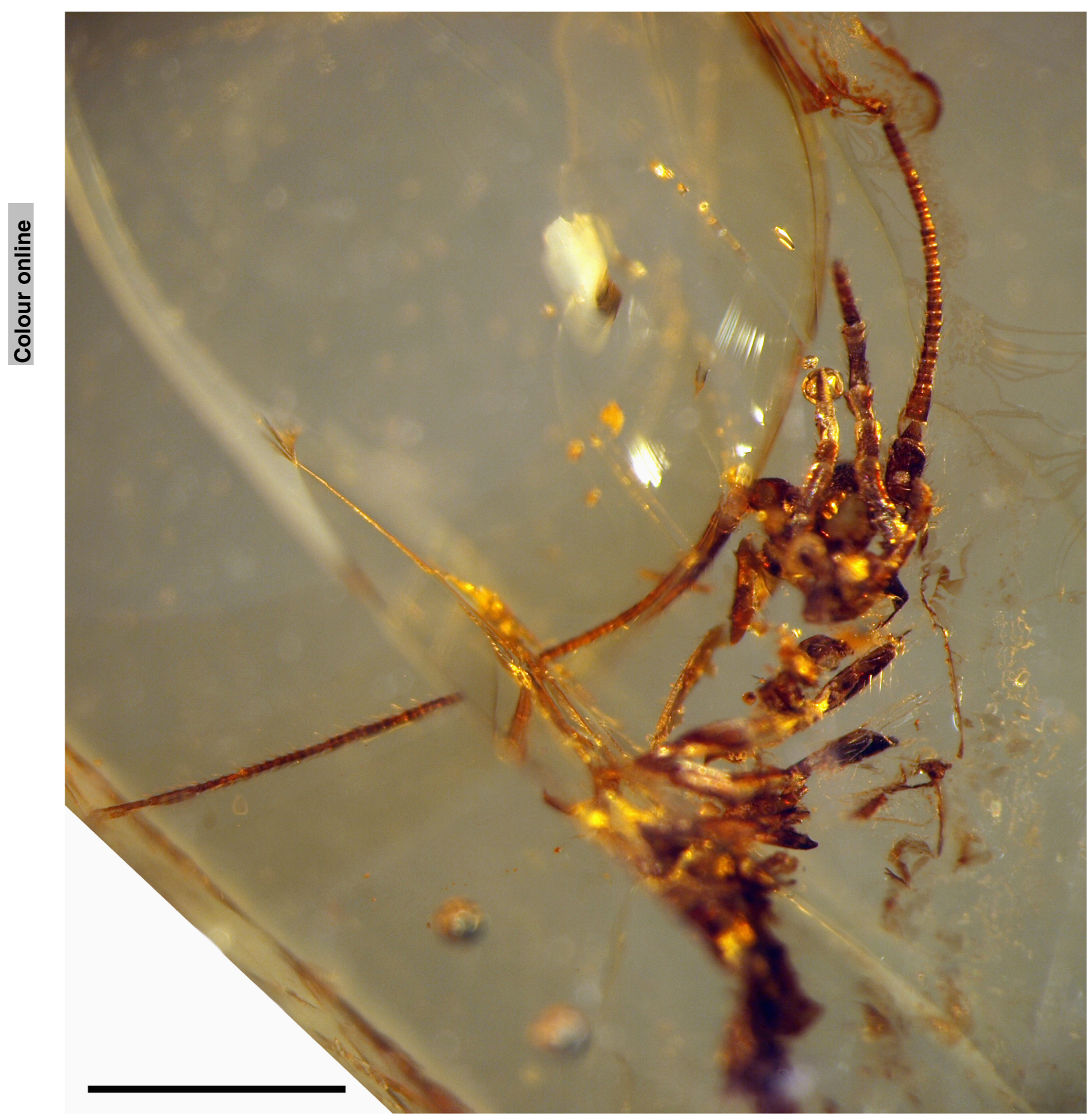

FIG. 2. Microphotograph of Glaesimeinertellus intermedius gen. et sp. nov. (holotype 1222, female), in ventral habitus, in Barremian amber from Hammana. Scale bar represents $1 \mathrm{~mm}$. Colour online.

distributed as follows: $\mathrm{P}_{6}$ with four spines along its length plus three spines distally, $\mathrm{P}_{7}$ with five distal spines around its apex. Labial palpus (Fig. 4A) 3-segmented, elongate, lengths of palpomeres $\left(\mathrm{P}_{1}-\mathrm{P}_{3}\right)$ 0.13, 0.14, and $0.20 \mathrm{~mm}$, respectively; $\mathrm{P}_{2}$ simple, without a protrusion; $\mathrm{P}_{3}$ only slightly widened distally (greatest width $0.08 \mathrm{~mm}$ ), with numerous distal sensilla basiconica (type D: Sturm \& Machida 2001) (Fig. 3) that are distinctly thicker than the surrounding setae; sensilla basiconica micro-denticulate at apex. Mandible not discernible.
Thoracic cuticle poorly preserved, proportions not measurable due to preservation. Legs with coxal styli present only on metacoxae (Fig. 3); metacoxal styli (Fig. 4B) fairly stout, length $0.16 \mathrm{~mm}$, width $0.04 \mathrm{~mm}$, with numerous elongate setae; forelegs not modified (e.g. not crassate), similar in form to mid- and hindlegs; femur, tibia and tarsus with ventral spiniform setae intermixed among thin, simple setae, those on the tarsus (Fig. 4C) shorter and thicker than those on the femur and tibia; tarsus length $0.32 \mathrm{~mm}$, with three tarsomeres (Fig. 4C); pretarsus with 


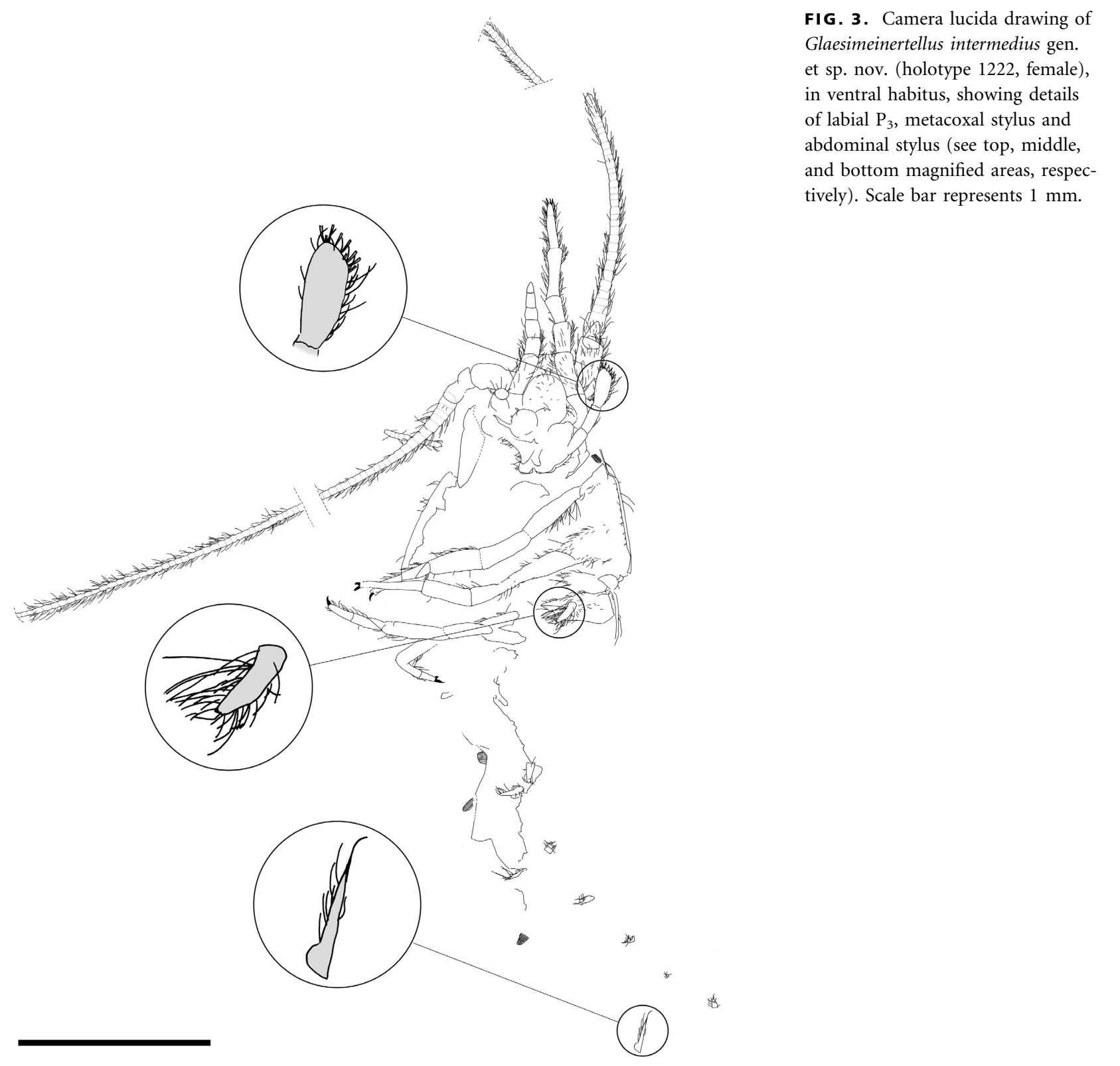

simple, paired claws (Fig. 4C); tarsal scopula (i.e. a brush-like patch of dense, often apically sinuate, specialized setae) absent.

Abdominal cuticle poorly preserved; abdominal coxites as well as corresponding sternites, and eversible vesicles not accessible as preserved; six pairs of abdominal styli visible (Fig. 3); all visible styli (Fig. 4D) of similar form, rather slender, width $0.02 \mathrm{~mm}$, with several fine, long setae more or less disposed in a longitudinal row; styli terminating in a distinct spine longer and thicker than neighbouring setae; length of stylus (without spine) $0.12 \mathrm{~mm}$; length of spine $0.06 \mathrm{~mm}$. Terminalia (genitalia, cerci, and median caudal filament) not preserved.

Male. Unknown.

Remarks. The new genus Glaesimeinertellus is readily distinguished from the other genera of Meinertellidae by the simple maxillary and labial palpi, the shape of the compound eyes, the slightly protruding frons, the not modified forelegs, the coxal styli only present on hindlegs, the presence of spiniform setae on legs, the trimerous tarsi without scopula, and the apical spine of abdominal styli thin and long.

Among the genera of Meinertellidae, only the fossil Unimeinertellus Zhang et al., and the modern Hypomachiloides Silvestri, Praemachilellus Sturm and Bach (both of the Hypomachiloides-group), and Machilontus Silvestri (Machilontus-group) have coxal styli restricted to the metacoxae (Sturm \& Machida 2001). However, the new fossil specimen can be distinguished from Unimeinertellus and Machilontus by the presence of a trimerous tarsi (vs dimerous) (Sturm \& Bach de Roca 1988). 


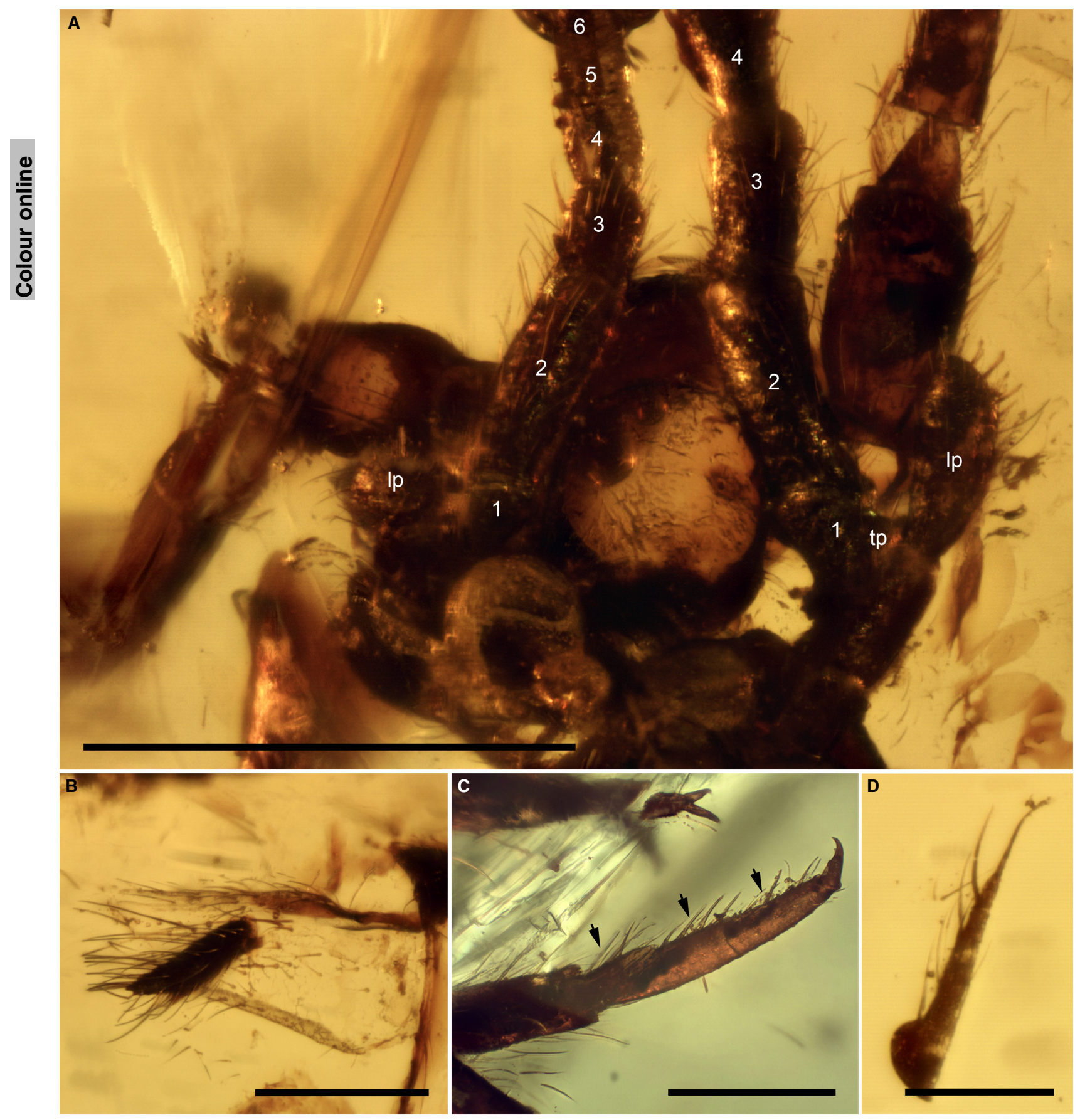

FIG. 4. Microphotographs of Glaesimeinertellus intermedius gen. et sp. nov. (holotype 1222, female). A, detail of head in ventral view, showing the maxillary and labial palpi. B, detail of metacoxal stylus. C, detail of tarsus, showing the three tarsomeres (arrows); D, detail of abdominal stylus. Abbreviations: 1-6, maxillary palpomeres; lp, labial palpus; tp, triangular process. Figures made with consecutive pictures taken at successive focal planes. Scale bars represent: $0.5 \mathrm{~mm}(\mathrm{~A}) ; 0.2 \mathrm{~mm}(\mathrm{~B}, \mathrm{C}) ; 0.1 \mathrm{~mm}$ (D). Colour online.

Conversely, Glaesimeinertellus shares with the genera Hypomachiloides and Praemachilellus the trimerous tarsi, but can be distinguished from them in its forelegs similar to mid- and hindlegs (vs stronger than mid- and hindlegs in both males and females) (Bach de Roca \& Sturm 1988;
Sturm \& Bach de Roca 1992; Packauskas \& Shofner 2010). Other differences worthy of mention relate to several secondary sexual characters. Indeed, males of both extant genera have the distal labial palpomeres distinctly and greatly widened (less markedly in females) (Bach de 
Roca \& Sturm 1988; Sturm \& Bach de Roca 1992; Sturm \& Machida 2001), while this condition is poorly developed in Glaesimeinertellus. Additionally, males of Hypomachiloides have the second article of the labial palp with a large apophysis on the inner border (reduced to a slight protrusion in females) (Bach de Roca \& Sturm 1988; Packauskas \& Shofner 2010), while the fossil lacks any protrusion.

Although present knowledge of bristletail ontogeny remains incomplete, the available data reveal that nearly all changes concern the postembryonic growth of some parts of the body largely resulting in the change of the relative proportions of some structures or the appearance of mature traits (e.g. labial palpus, coxal styli, eversible abdominal vesicles, terminalia), and leading gradually and qualitatively to the adult stage (Bach de Roca \& GajuRicart 1987; Sturm \& Machida 2001). However, comparable data on the growth of the different parts and duration of the early stages are scarce. Taking into consideration the body length $(c .4 .0 \mathrm{~mm})$ of the fossil, the holotype of G. intermedius might correspond to a scaled juvenile or a sub-adult (Sturm \& Machida 2001). The form of the labial palpi (with $\mathrm{P}_{2}$ lacking any process and $\mathrm{P}_{3}$ only slightly widened) and the maxillary palpi (with $\mathrm{P}_{2}$ lacking any process) raise the question as to whether these are plesiomorphic absences in an adult, or whether they are absent owing to the individual representing a non-adult stage. However, the presence of a well-developed metacoxal stylus (a trait that also tends to correlate with ontogenetic stage), supports the conclusion that the simple labial and maxillary palpi are true characters for Glaesimeinertellus, it is likely that it corresponds to a female.

Occurrence. Lower Cretaceous (Barremian; Maksoud et al. 2017), Hammana outcrop, Caza Baada (Baabda District), Mouhafazit Jabal Libnen (Mount Lebanon Governorate), central Lebanon.

\section{Genus MACROPSONTUS Silvestri, 1911 Macropsontus bachae sp. nov. Figures 5-7}

LSID. urn:lsid:zoobank.org:act:F1DAE74C-25DD-4BBB-AD7F02D59B15D49F

Derivation of name. The specific epithet honours Prof. Carmen Bach de Roca, Universitat Autònoma de Barcelona (Bellaterrra, Spain), for her outstanding contributions to our knowledge of the Archaeognatha.

Type specimen. 1565 (coll. Azar), holotype; juvenile of indeterminate sex; virtually complete except for the antennae and terminalia, and observable dorsally and ventrally; preserved in a thin section of transparent yellow amber together with several coprolites and plant remains (syninclusions).

Diagnosis (sex unknown, juvenile). Maxillary $\mathrm{P}_{2}$ without a hook-like process, bearing two setae $2 \times$ longer than greatest palpomere diameter; labial $\mathrm{P}_{2}$ without a protusion; labial $\mathrm{P}_{3}$ slightly widened distally, with numerous sensilla basiconica (type D); compound eyes large and rounded; ocelli sole-shaped; frons slightly protruding; profemora not wider than meso- and metafemora; all legs without coxal styli; spiniform setae present on legs; tarsi dimerous, without scopula; second abdominal sternite enlarged; $1+1$ eversible vesicles on abdominal segments; apical spine of abdominal styli thin and long.

Description (sex unknown, juvenile). Sex unknown (juvenile). Body (Figs 5, 6) nearly complete, length as preserved $2.66 \mathrm{~mm}$, covered with scales (scale pattern indiscernible); appendages devoid of scales.

Head (Fig. 7A) orthognathous, rounded in dorsal view, length $0.30 \mathrm{~mm}$, about $0.11 \times$ total body length as preserved, width $0.30 \mathrm{~mm}$; frons slightly protruding, with few short setae. Compound eyes (Fig. 7C) large (length $0.18 \mathrm{~mm}$ ), flattened, roundshaped, holoptic, and composed of many ommatidia (average diameter of ommatidia $0.01 \mathrm{~mm}$ ); ratio length/width of compound eyes close to 1 (i.e. isodiametric); ratio length of contact line/length of compound eye close to 1 . Ocelli sole-shaped. Antenna (Fig. 7A) incomplete, length as preserved $0.81 \mathrm{~mm}$; scape not robust, length $0.11 \mathrm{~mm}$, width $0.07 \mathrm{~mm}$; pedicel length $0.06 \mathrm{~mm}$, width $0.06 \mathrm{~mm}$; flagellum with distinct breakpoints separated by seven flagellomeres; each flagellomere bearing one or two whorls of long, slender, curved, acuminate setae. Maxillary palpus (Fig. 7B) 7-segmented, thin, with abundant, simple setae; $\mathrm{P}_{1}$ obscured as preserved (triangular process not discernible); $\mathrm{P}_{2}$ without a hook-like process, bearing two setae $2 \times$ longer than greatest palpomere diameter; $\mathrm{P}_{7}$ conical, somewhat shorter than $\mathrm{P}_{6} \quad\left(\mathrm{P}_{7} / \mathrm{P}_{6}\right.$ length ratio (0.04/0.06) 0.66), although measurements possibly underestimated due to foreshortened position; $\mathrm{P}_{5}-\mathrm{P}_{7}$ with dorsal hyaline spines distributed as follows: $\mathrm{P}_{5}$ with two distal spines, $\mathrm{P}_{6}$ with three distal spines, and $\mathrm{P}_{7}$ with three distal spines. Labial palpus (Fig. 7B) 3-segmented, elongate, lengths of palpomeres $\left(\mathrm{P}_{1}-\mathrm{P}_{3}\right) 0.05,0.06$, and $0.09 \mathrm{~mm}$, respectively; $\mathrm{P}_{2}$ without a protusion, $\mathrm{P}_{3}$ only slightly widened distally (greatest width $0.03 \mathrm{~mm}$ ), with numerous distal sensilla basiconica (type D) that are distinctly ticker than surrounding setae; sensilla basiconica micro-denticulate at apex. Labium (Fig. 7B) with bilobed endites (two glossae and two paraglossae).

Thorax (Figs 5A, 7A) $0.64 \mathrm{~mm}$ in length, about $0.24 \times$ the total body length as preserved; pronotum length $0.13 \mathrm{~mm}$, width $0.35 \mathrm{~mm}$; mesonotum length $0.34 \mathrm{~mm}$, width $0.39 \mathrm{~mm}$; metanotum only slightly shorter than mesonotum, length $0.30 \mathrm{~mm}$, width $0.38 \mathrm{~mm}$; spiniform setae not present on lateral margins of terga. Legs (Fig. 6) without coxal styli; forelegs not modified, similar in form to mid- and hindlegs; femur and tibia subequal in length; tarsus longer than tibia, with ventral spiniform setae 


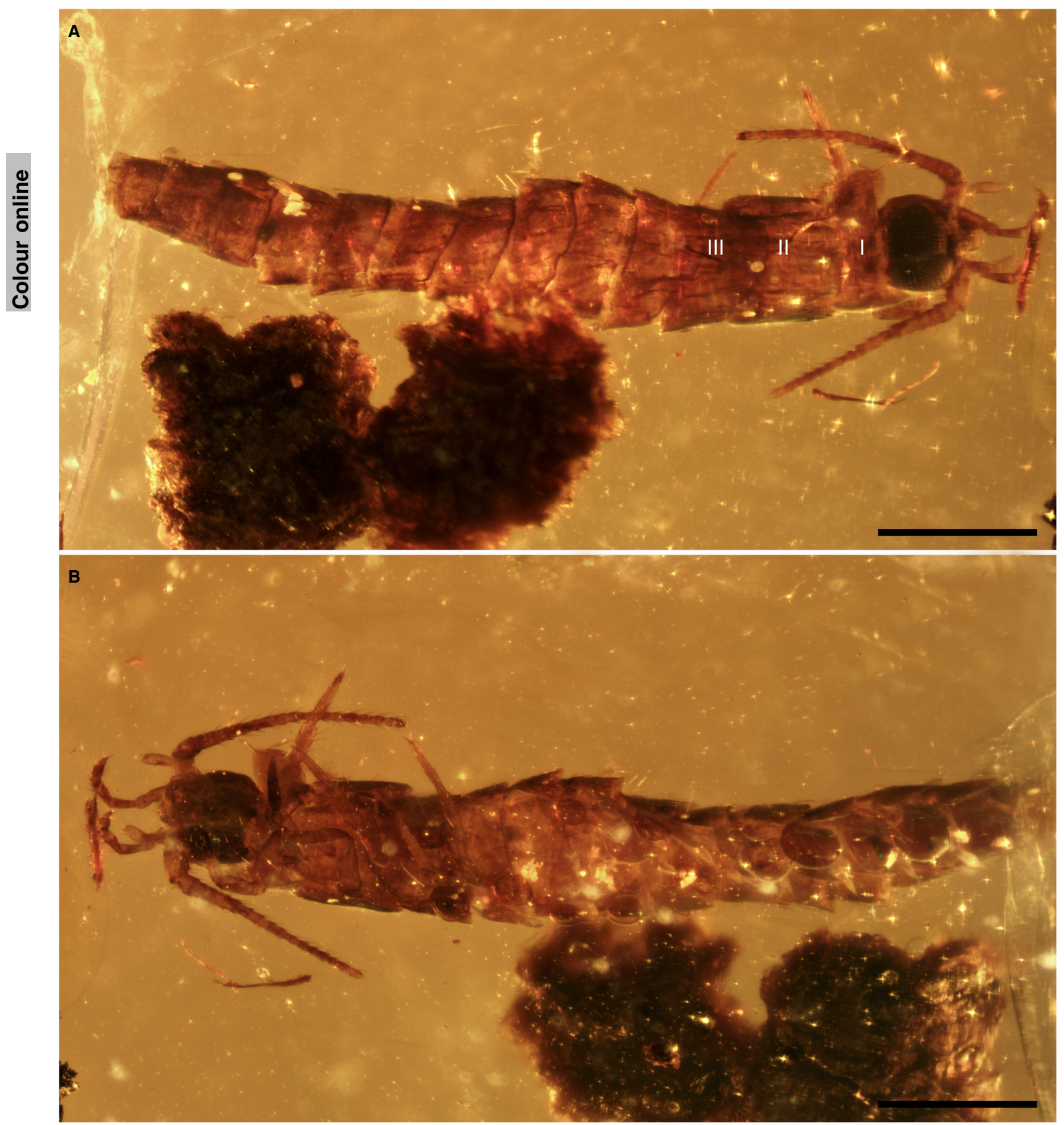

FIG. 5. Microphotographs of Macropsontus bachae sp. nov. (holotype 1565), in Barremian amber from Hammana. A, dorsal habitus (thoracic terga have been tagged with Roman numerals). B, ventral habitus. Figures made with consecutive pictures taken at successive focal planes. Scale bars represent $0.5 \mathrm{~mm}$. Colour online.

intermixed among thin, simple setae; tarsus length $0.18 \mathrm{~mm}$, with two tarsomeres (Fig. 7D); pretarsus with simple, paired claws (Fig. 7D); tarsal scopula absent.

Abdomen $1.84 \mathrm{~mm}$ in length, about $0.69 \times$ the total body length, with seven pairs of abdominal styli visible on coxites III-
IX (Fig. 6); all visible styli (Fig. 7E) of similar form, rather slender, width $0.02 \mathrm{~mm}$, with several fine, long setae more or less disposed in a longitudinal row; styli terminating in a distinct spine longer and thicker than neighbouring setae; length of stylus (without spine) $0.10 \mathrm{~mm}$, length of spine $0.04 \mathrm{~mm}$; 


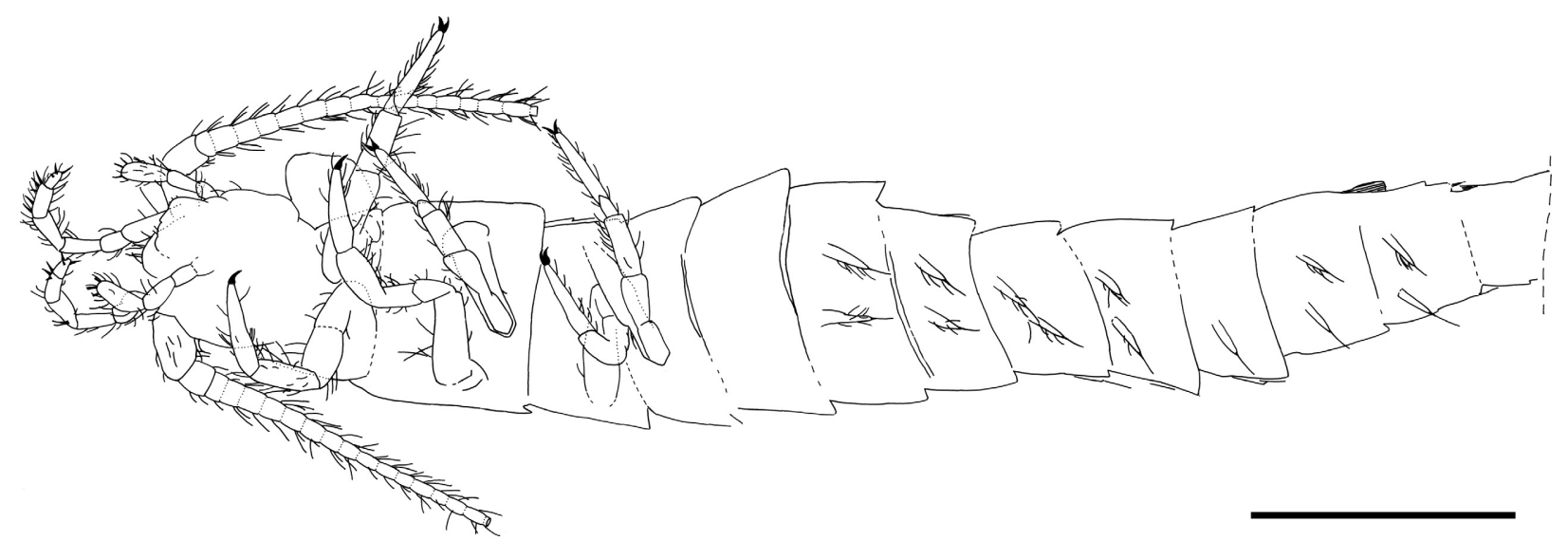

FIG. 6. Camera lucida drawing of Macropsontus bachae sp. nov. (holotype 1565), in ventral habitus. Scale bar represents $0.5 \mathrm{~mm}$.

abdominal sternite II enlarged; $1+1$ eversible vesicles (Fig. 7E) visible on some abdominal segments; length and width of abdominal segments I-X (in $\mathrm{mm}$ ): I: $0.22,0.42$; II: $0.19,0.44$; III: $0.19,0.43$; IV: $0.16,0.34$; V: $0.18,0.31$; VI: $0.19,0.31$; VII: $0.18,0.31$; VIII: $0.20,0.29$; IX: $0.18,0.25$; X: $0.14,0.20$. Genitalia not accessible as preserved (probably not developed). Cerci and median caudal filament not preserved.

Remarks. Dimerous tarsi only occur in four genera of Meinertellidae (the extant Hypermeinertellus Paclt, Macropsontus Silvestri, and Machilontus Silvestri, and the fossil Unimeinertellus Zhang et al.), and this has been widely interpreted to be a derived feature among Archaeognatha (Sturm \& Machida 2001; Mendes \& Wunderlich 2013). Unlike Hypermeinertellus, Macropsontus bachae lacks a tarsal scopula (highly developed in Hypermeinertellus and related taxa in the Meinertellus-group of genera except Neomachilellus Wygodzinsky) (Sturm \& Machida 2001). As for the genera Macropsontus and Machilontus (both of the Machilontus-group) Macropsontus bachae shares the very large compound eyes, lateral ocelli sole-shaped, terminal labial palpomeres only moderately widened distally, spiniform setae present on legs, tarsi lacking scopulae, and enlarged second abdominal sternite (Sturm \& Machida 2001). However, the absence of meso- and metacoxal styli is in accordance with Macropsontus and contradicts its inclusion within Machilontus as well as the fossil Unimeinertellus. Indeed, the genus Macropsontus is principally differentiated from Machilontus by the aforementioned absence of meso- and metacoxal styli (while metacoxal styli are present in Machilontus), and the presence of a hook with a long cylindrical base on the male maxillary $\mathrm{P}_{2}$ (if present, the cylindrical base is shorter than half the length of the hook in Machilontus) (Sturm \& Bach de Roca 1988). Admittedly, the present fossil lacks the maxillary $\mathrm{P}_{2}$ hook (a secondary sexual feature in adult males) and one might interpret that feature could exclude the species from
Macropsontus. However, the small size of the specimen suggests that it was juvenile, and therefore would have lacked the secondary sexual traits of the adult or it may have been a female, and thus the absence of the maxillary $\mathrm{P}_{2}$ hook is not greatly informative in this case. Macropsontus also differs from the fossil in the tendency to protrusion on the second labial palpomere (Sturm \& Bach de Roca 1988). Thus, in the absence of further data, we have conservatively placed the present fossil within Macropsontus. It is possible that if other features were discernible (e.g. details of the genitalia), then this Lower Cretaceous species might be better classified in a separate genus, but this must await more completely preserved material.

Occurrence. Lower Cretaceous (Barremian; Maksoud et al. 2017), Hammana outcrop, Caza Baada (Baabda District), Mouhafazit Jabal Libnen (Mount Lebanon Governorate), central Lebanon.

\section{Macropsontus azari sp. nov. Figures 8, 9}

LSID. urn:lsid:zoobank.org:act:0181426F-FB84-4FCA-9D5C0BA755E94D53

Derivation of name. The specific epithet honours Dr Dany Azar, Lebanese University (Beirut, Lebanon), whose work has given renewed vitality to the study of the numerous and significant amber-bearing deposits of Lebanon and their palaeobiological content.

Type specimen. RIH-2A (coll. Azar), holotype; juvenile of indeterminate sex; virtually complete, and observable in lateral view; preserved in a thin section of transparent yellow amber; the piece also contained a coccid male (RIH-2B) as syninclusion. 


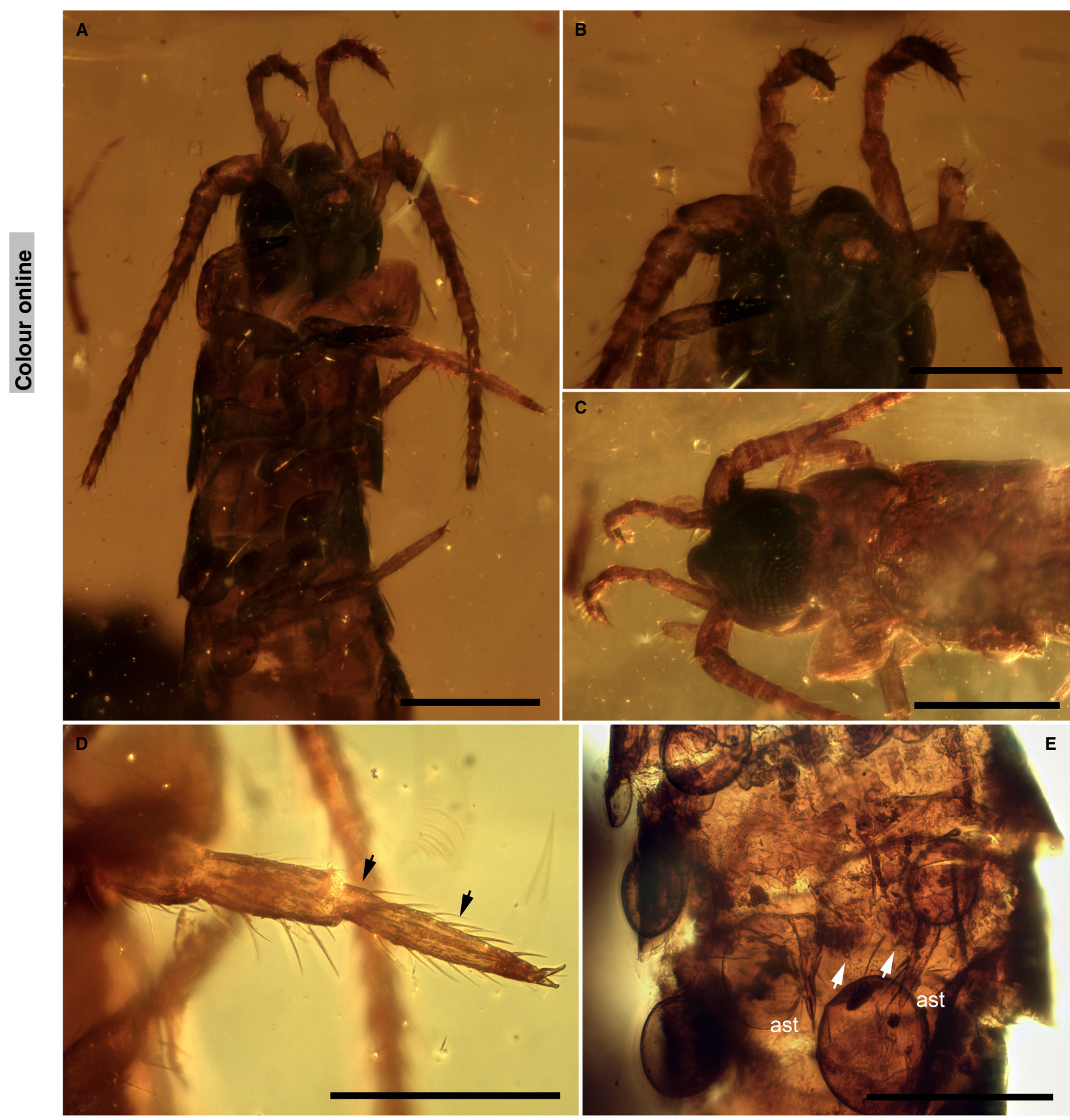

FIG. 7. Microphotographs of Macropsontus bachae sp. nov. (holotype 1565). A, anterior part of the body in ventral view. B, magnified view of mouthparts from A. C, anterior portion of the body in dorsal view. D, magnified view of tarsus from A, showing the two tarsomeres (arrows). E, abdomen showing the sternite development, abdominal eversible vesicles (arrows) and styli. Abbreviations: ast, abdominal styli. Figures made with consecutive pictures taken at successive focal planes. Scale bars represent: $0.3 \mathrm{~mm}(\mathrm{~A}, \mathrm{C}) ; 0.2 \mathrm{~mm}$ (B, D, E). Colour online.

Diagnosis (sex unknown, juvenile). Maxillary $\mathrm{P}_{2}$ without a hook-like process, with no special setae; labial $\mathrm{P}_{3}$ slightly widened distally, with numerous sensilla basiconica (type D); compound eyes large and rounded; frons slightly protruding; profemora not wider than meso- and metafemora; all legs without coxal styli; spiniform setae present on legs; tarsi dimerous, without scopula; apical spine of abdominal styli thin and long; cerci very short, ending 


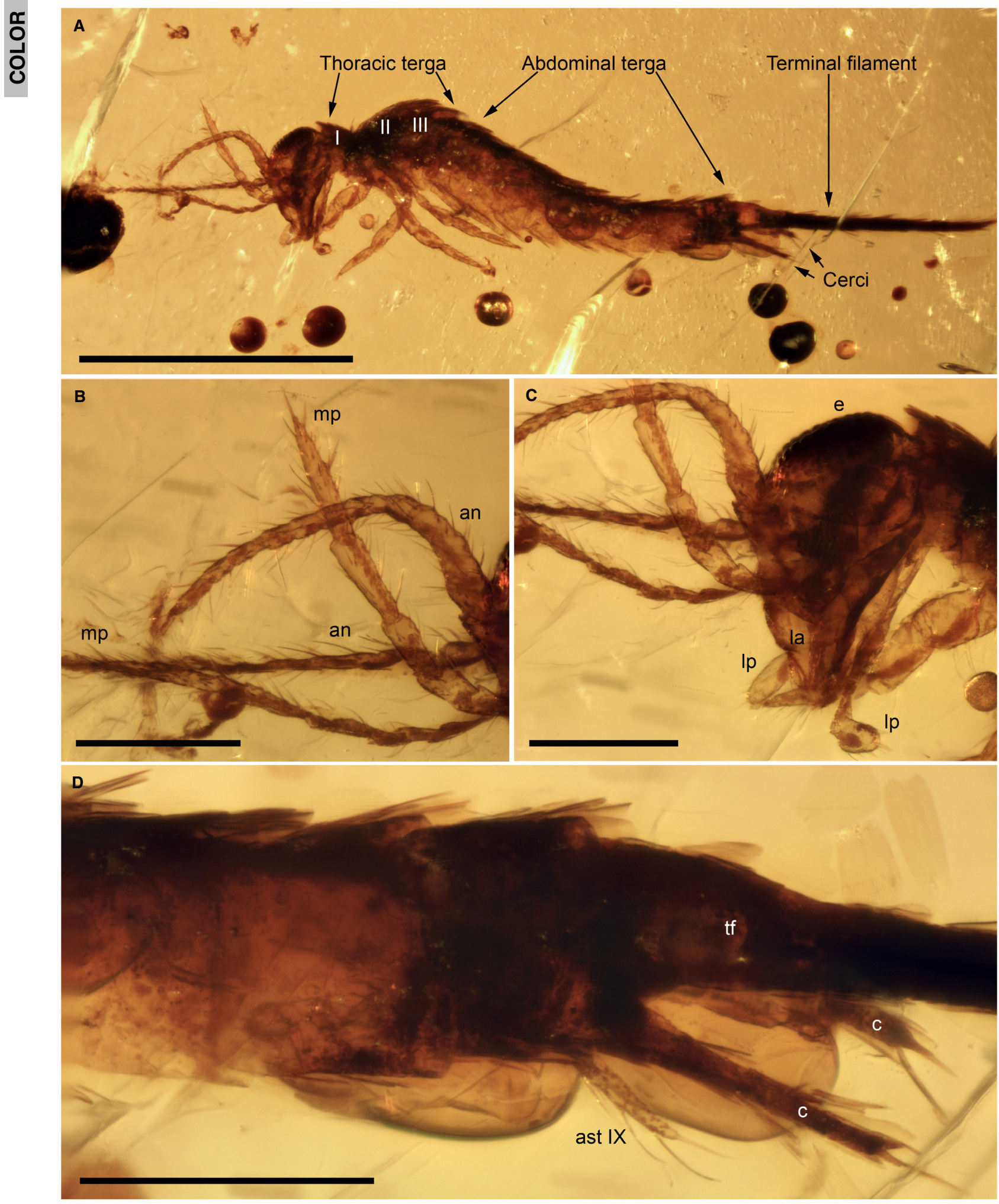

FIG. 8. Microphotographs of Macropsontus azari sp. nov. (holotype RIH-2A), in Barremian amber from Al-Rihan. A, lateral habitus. B, detail of maxillary palpi and antennae. C, detail of head. D, detail of posterior part of abdomen, cerci, and median caudal filament. Abbreviations: an, antenna; ast IX, abdominal stylus IX; c, cercus; e, compound eye; la, lacinia; lp, labial palpus; mp, maxillary palpus; tf, terminal filament. Figures made with consecutive pictures taken at successive focal planes. Scale bars represent: $1 \mathrm{~mm}(\mathrm{~A}) ; 0.2 \mathrm{~mm}$ (B-D). Colour online. 


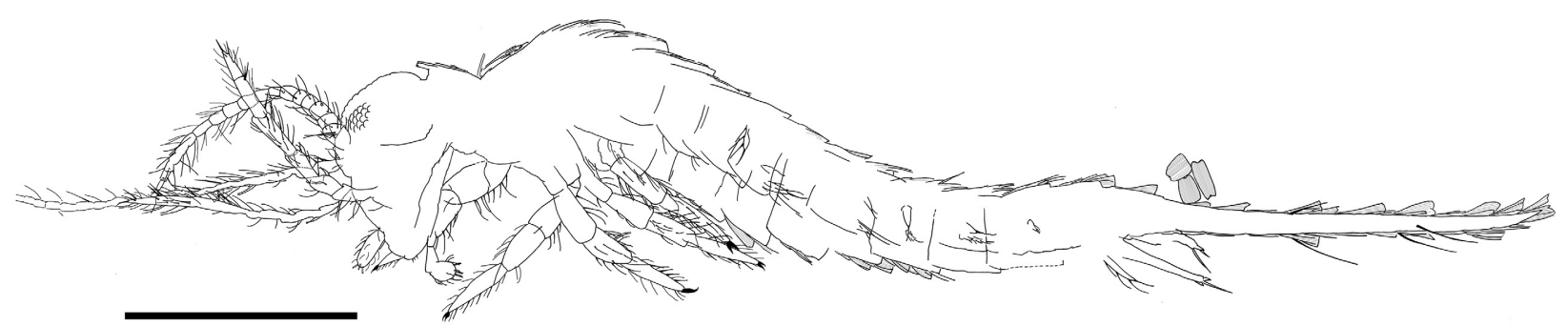

FIG. 9. Camera lucida drawing of Macropsontus azari sp. nov. (holotype RIH-2A), in lateral habitus. Scale bar represents $0.5 \mathrm{~mm}$.

with an apical spine and two longer subapical setae on each side of the spine.

Description (sex unknown, juvenile). Body (Figs 8A, 9) length $1.70 \mathrm{~mm}$, with elongate habitus, transverse section rounded along body length; abundant scales on all terga (scale pattern indiscernible), abdominal coxites, cerci, and median caudal filament, but scales absent on appendages; some pigmentation detectable on dorsal part of head and body.

Head (Fig. 8C) shape subtriangular in lateral view due to elongate mouthparts, orthognathous; cephalic diagonal $0.42 \mathrm{~mm}$, length $0.24 \mathrm{~mm}$, about $0.14 \times$ the total body length; frons slightly protruding, with at least two long setae and several short setae. Compound eyes (Fig. 8C) large (length $0.19 \mathrm{~mm}$ ), flattened, apparently round-shaped (although width not measurable), holoptic, and composed of many ommatidia (average diameter of ommatidia $0.01 \mathrm{~mm}$ ); exact ocular ratios (length/ width of compound eye, and length of contact line/length of compound eye) not measurable due to nature of preservation (dorsal and frontal views are not possible as preserved). Ocelli not accessible. Antenna (Fig. 8B) incomplete, length as preserved $0.79 \mathrm{~mm}$; scape poorly visible, length c. $0.09 \mathrm{~mm}$, width $0.06 \mathrm{~mm}$; pedicel length $0.07 \mathrm{~mm}$, width $0.05 \mathrm{~mm}$; breakpoints of flagellum not discernible; each flagellomere bearing one or two whorls of long, slender, curved, acuminate setae. Maxillary palpus (Fig. 8B) 7-segmented, thin, with abundant, simple setae; $\mathrm{P}_{1}$ obscured as preserved (triangular process not discernible); $\mathrm{P}_{2}$ without a hook-like process, with setae similar to those of the others palpomeres (never longer than greatest palpomere diameter); $\mathrm{P}_{7}$ conical, somewhat shorter than $\mathrm{P}_{6}\left(\mathrm{P}_{7} / \mathrm{P}_{6}\right.$ length ratio (0.07/0.10) 0.70); $\mathrm{P}_{5}-\mathrm{P}_{7}$ with dorsal hyaline spines distributed as follows: $\mathrm{P}_{5}$ with one distal spine; $\mathrm{P}_{6}$ with three distal spines; $\mathrm{P}_{7}$ with three distal spines (one terminal). Labial palpus (Fig. 8C) 3-segmented, elongate; $\mathrm{P}_{1}$ and $\mathrm{P}_{2}$ poorly visible as preserved; $\mathrm{P}_{3}$ length $0.10 \mathrm{~mm}$, only slightly widened distally (greatest width $0.03 \mathrm{~mm}$ ), with numerous distal sensilla basiconica (type D) that are distinctly thicker than surrounding setae; sensilla basiconica micro-denticulate at apex. Mandible (Fig. 8C) with several teeth (precise number not discernible as preserved).

Thorax (Fig. 8A) $0.32 \mathrm{~mm}$ in length, about $0.19 \times$ the total body length, strongly arched; spiniform setae not present on lateral margins of terga. Legs (Fig. 9) without coxal styli (although the coxa and trochanter are poorly visible due to preservation); forelegs not modified, similar in form to mid- and hindlegs, the left profemur and protibia compressed and taphonomically altered giving a crassate appearance; femur and tibia subequal in length; tarsus longer than tibia, with ventral spiniform setae intermixed among thin, simple setae; tarsus length $0.15 \mathrm{~mm}$, with two tarsomeres (Fig. 9); pretarsus with simple, paired claws (Fig. 9); tarsal scopula absent.

Abdomen (Fig. 8A) $1.15 \mathrm{~mm}$ in length, about $0.68 \times$ the total body length; abdominal coxites as well as corresponding sternites, and eversible vesicles not accessible as preserved; abdominal styli poorly visible (Fig. 9); all visible styli (Fig. 8D) of similar form, rather slender, width $0.02 \mathrm{~mm}$, with several fine, long setae more or less disposed in a longitudinal row; styli terminating in a distinct spine longer and thicker than neighbouring setae; length of stylus (without spine) $0.09 \mathrm{~mm}$; length of spine $0.05 \mathrm{~mm}$. Genitalia not accessible as preserved (probably not developed). Cerci and median caudal filament complete; median caudal filament (Figs 8A, 9) length $0.97 \mathrm{~mm}$, about $0.57 \times$ of total body length, with dense scales and sparsely scattered, long, sensory, spine-like setae; cerci (Fig. 8A, D) very short, scarcely exceeding abdominal apex, length $0.23 \mathrm{~mm}$, about $0.24 \times$ the length of median caudal filament, densely covered by scales, ending with an apical spine and two longer subapical setae on each side of the spine.

Remarks. As already noted (refer to remarks for Macropsontus bachae sp. nov., above), the presence of dimerous tarsi is not common among Archaeognatha. For many of the same reasons outlined for the specimen from Hammana outcrop, the present fossil can also be placed within the extant genus Macropsontus. Indeed, the absence of tarsal scopulae excludes the dimerous Hypermeinertellus and the absence of coxal styli excludes the dimerous Machilontus. The setation of the second maxillary palp, immediately distinguishes $M$. azari from the other Macropsontus species described in this paper. While M. azari has setae never longer than the greatest palpomere diameter and uniformly distributed along the maxillary palp, M. bachae has a second maxillary palp with two setae twice longer than the greatest palpomere diameter. Unfortunately, other diagnostic characters of M. bachae are not preserved or are poorly visible in M. azari (i.e. labial $\mathrm{P}_{2}$ without a protusion; ocelli sole-shaped; second abdominal sternite enlarged; $1+1$ eversible vesicles on abdominal segments), meaning that it is impossible to establish if they differ in the two species. In the case of the specimen of M. azari, the small body size and the absence of secondary sexual traits is in agreement with the exceptionally reduced cerci (scarcely exceeding the 


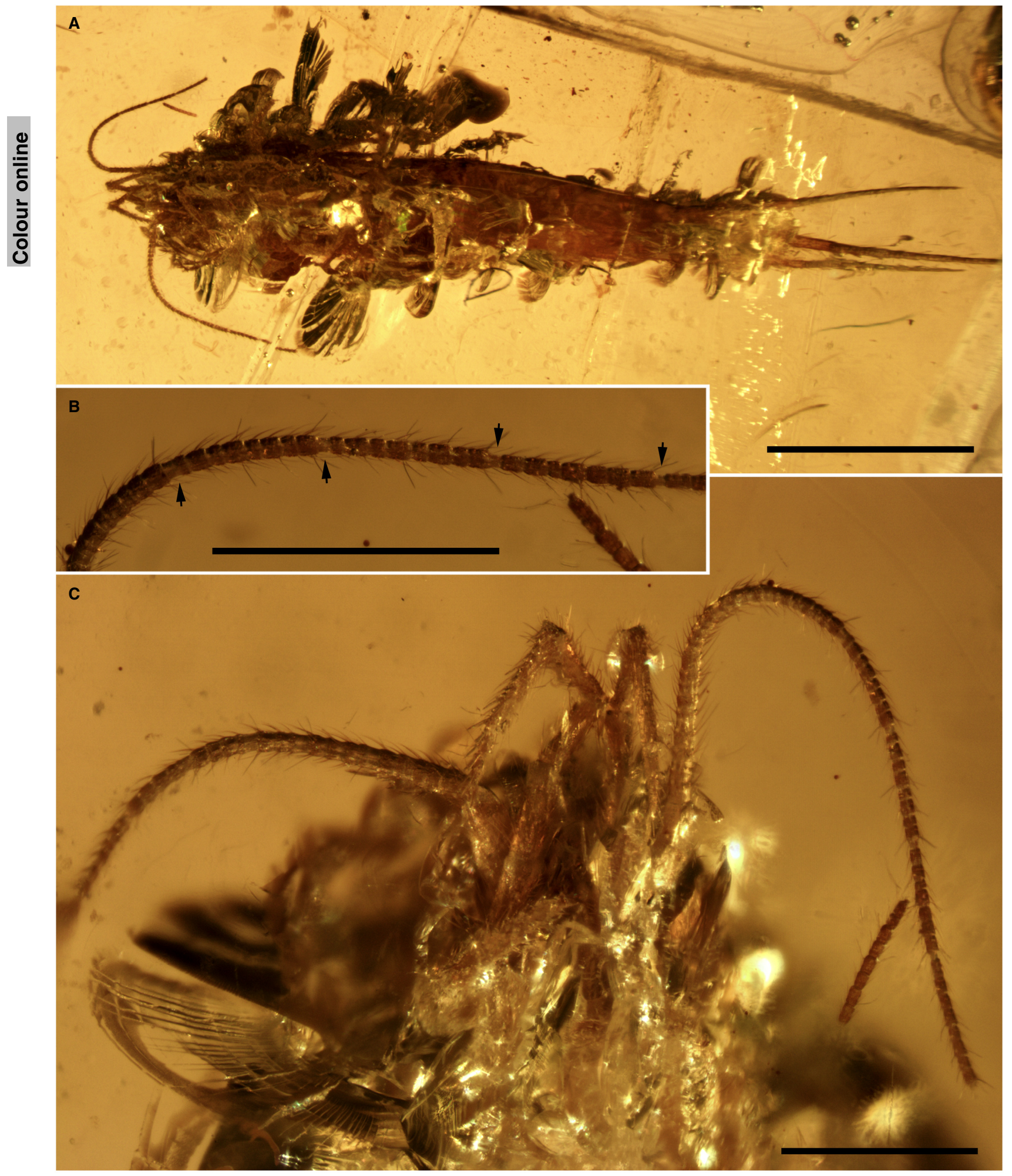

FIG. 10. Microphotographs of meinertellid specimen RIH-4A, in Barremian amber from Al-Rihan. A, ventral habitus. B, detail of antennae showing the breakpoints along the flagellum (arrows); note that the breakpoints are easily recognizable by their narrowed diameter and lack of setae. C, detail of head in ventral view. Scale bars represent: $2 \mathrm{~mm}$ (A); $0.5 \mathrm{~mm}$ (B, C). Colour online. 
abdominal apex), and the specimen most likely corresponds to a juvenile.

Occurrence. Lower Cretaceous (Barremian; Maksoud et al. 2017), Al-Rihan outcrop, Caza Jezzine (Jezzine Department), Mohafazat Loubnan El-Janoubi (South Lebanon Governorate), southern Lebanon.

Gen. et sp. indet.

Figure 10

Material. Specimen RIH-4A (coll. Azar); the amber piece originally contained a spider (RIH-4B), an unidentified ceratopogonid (RIH-4E), and a mite and an undetermined brachyceran fly (both as RIH-4CD) as syninclusions.

Descriptive notes. Specimen observable in dorsal and ventral views, preserved in brittle amber with multiple internal fractures that hinder examination (Fig. 10A), only with antennae, maxillary palpi, and terminalia partly visible with some detail. Body (Fig. 10A) length $5.91 \mathrm{~mm}$, greatest width as preserved $1.10 \mathrm{~mm}$. Antenna (Fig. 10B, C) incomplete, length as preserved $2.08 \mathrm{~mm}$, devoid of scales; scape and pedicel poorly visible; flagellum with distinct breakpoints (Fig. 10B), these separated by stretches of 7-8 flagellomeres; each flagellomere bearing one or two whorls of long, slender, curved, acuminate setae. Maxillary palpus (Fig. 10C) thin, densely setose; maxillary $\mathrm{P}_{5}-\mathrm{P}_{7}$ with dorsal and apical spines. Median caudal filament (Fig. 10A) incomplete, length as preserved $2.76 \mathrm{~mm}$; cercus length $2.16 \mathrm{~mm}$; median caudal filament and cerci (Fig. 10A) with dense scales and sparsely scattered, long, sensory, spinelike setae.

Remarks. The above specimen is too poorly preserved to permit conclusive assignment to any particular genus or species but the observable details (e.g. antennae and maxillary and labial palpi devoid of scales) are indicative of a meinertellid.

Occurrence. Lower Cretaceous (Barremian; Maksoud et al. 2017), Al-Rihan outcrop, Caza Jezzine (Jezzine Department), Mohafazat Loubnan El-Janoubi (South Lebanon Governorate), southern Lebanon.

\section{DISCUSSION}

The fauna of Archaeognatha preserved in Lebanese amber is, at present, the earliest documented source of the group with sufficient preservation to provide character data comparable to modern forms. All the specimens can be placed within the extant superfamily Machiloidea. Apomorphies of machiloids (summarized by Sturm \&
Machida 2001) include the presence of lateral cranial lobes that include the mandibular condyle (mandibular overhang); large and contiguous compound eyes; hypertrophic maxillary palpi, with seven palpomeres typically longer than the mesothoracic appendages; maxillary $\mathrm{P}_{1}$ with a dorsal triangular process; bilobed labial endites; metacoxae, and sometimes also mesocoxae, with styli that cannot be actively moved; and caudal appendages with scales. Most of these characters are easily observed in the studied material. Furthermore, the newly described specimens can be placed within the Meinertellidae, a family characterized by having small abdominal sternites, a longitudinal projection on the base of maxillary palp, the maxillary $\mathrm{P}_{1}$ with two inner humps, the male maxillary $\mathrm{P}_{2}$ with a hook-like process dorsoapically, the absence of paramera, and the absence of scales on the antennae, palpi, legs and styli (Sturm \& Machida 2001; Zhang et al. 2018). Currently, there are four informal, suprageneric groups recognized within Meinertellidae (the Machiloides, Hypomachiloides-, Machilontus- and Meinertellusgroups), as well as the unplaced genus Machilinus Silvestri (Sturm \& Machida 2001). It is not clear to what degree these might represent natural groups, and there is considerable need for a revision of extinct phylogenetic concepts among meinertellids. The differences between the genera of Archaeognatha are rather subtle, and most of the taxa show a distressingly confusing mosaic of conserved and highly labile features (i.e. plesiomorphies and homoplasies), whose combinations are used to characterize the groups, but necessitating various exceptions. Overall, the pattern of relationships is rather opaque, further emphasizing the need for greater investigation and perhaps the application of genomic data.

Despite preservation in comparatively clear amber and the fine preparations available to us, many details commonly examined among living Archaeognatha were simply not preserved (e.g. terminalia), or were not visible due to concealed positions in the fossils (e.g. the hooks of the maxillary palpi or the genitalia). Nonetheless, diagnostic characters from the general shape of the body and proportions of segments, structure of the antennae and maxillary and labial palpi, as well as coxal styli and tarsal configurations, are informative and allow the comparison between fossil and modern forms.

Cretaceomachilis libanensis, also in Lebanese amber (Jouar Es-Souss outcrop in Bkassine, southern Lebanon; Azar et al. 2010), was reported to be related to the Machiloides-group (currently including the genera Machiloides Silvestri, Nesomachilis, and the recently synonymized Allomachilis Silvestri and Kuschelochilis Wygodzinsky) (Mendes et al. 2009), based on the presence of meso- and metacoxal styli (Sturm \& Poinar 1998). More specifically, C. libanensis was considered a relative of Machiloides based on the moderately 
protrudent frons, sole-shaped lateral ocelli, apical labial palpomere that is not distinctly broadened, and the trimerous tarsi (Sturm \& Poinar 1998). Lately, Zhang et al. (2018) described one more species of Cretaceo5 machilis, C. longa Zhang et al., based on a female specimen in Cenomanian amber from Myanmar, allowing the redescription of the genus. Therefore, the list of Lebanese Archaeognatha increases to four species in two genera.

The considerable anatomical homogeneity of the order and the subtle differences among seemingly homoplastic features, while posing a considerable challenge for the study of extant groups, are even more problematic when dealing with fossil material of varying degrees of completeness. The generalized appearance of living and fossil Archaeognatha has apparently remained little changed over at least the last 129 or more million years. This bradytely is much like that of other arthropods with similar subcortical, litter, or crevice habitats (Engel \& Grimaldi 2002; Cognato \& Grimaldi 2009; Chatzimanolis et al. 2013; Engel et al. 2016; Sánchez-García \& Engel 2016a, $b$ ), and perhaps reflects a long-term consistency of the microenvironment in which they pass out their lives (Hamilton 1978). It is not until the Palaeozoic, or perhaps the mid-Triassic, that there may be found taxa that deviate sufficiently as to fall outside of crown-group Machiloidea (i.e. the previously discussed Dasyleptidae). From this, it seems clear that glimpses into the basal divergences among Archaeognatha must await Palaeozoic material with sufficient preservation as to permit fine comparisons with the modern and Cretaceous taxa.

\section{CONCLUSION}

The study of Archaeognatha has been generally hampered by their overall morphological conservatism and the lack of robust phylogenetic estimates from which to determine the polarity and consistency of traits often used in bristletail systematics. There are apparently repeated losses and appearances of suites of characters, and it is unclear to what degree these are valid in supporting particular clades (Sturm \& Machida 2001). Added to this is a limited understanding of intraspecific variability among ontogenetic stages, with only the tiniest fraction of species having been examined and yet large swaths of palaeontological material are of sundry juvenile instars (e.g. Dasyleptidae: Rasnitsyn 1999). This reality certainly poses problems when attempting to consider fossil Archaeognatha, with varied forms of and degrees of completeness in preservation. Even among some of the most well understood fossil insects, there is rarely a strong understanding of potential sexual dimorphism or changes among life stages. Despite these setbacks, incremental progress can be made through the continued documentation of available fossil material and their unique character combinations in comparison with modern counterparts. As such, fossil Archaeognatha, even immature stages, should not be ignored and while taxonomic uncertainties may persist, as is true for any lineage, it is only through the discovery and description of new material that resolution of long-standing questions in bristletail evolution may be achieved (Haug et al. 2015). Here we have provided an overview of bristletail diversity in the Lebanese amber fauna, building and expanding upon the body of data available for understanding the Cretaceous evolution of this basal insect order.

Acknowledgements. We are grateful to Dr Dany Azar, Lebanese University (Beirut), for the preparation and loan of the specimens presented herein; to Dr André Nel, Muséum national d'Histoire naturelle (Paris), for his advice during a research stay at the MNHN; and to Dr Carmen Bach de Roca, Universitat Autònoma de Barcelona (Bellaterra), for aid with discussions regarding the new fossil specimens. Partial support for this work was provided by the SYNTHESYS Project (FR-TAF-3362), financed by the European Community Research Infrastructure Action under the FP7 'Capacities' Program. This study is a contribution to the Spanish Ministry of Economy and Competitiveness Projects AMBERIA CGL2014-52163, and AEI/FEDER, UE Grant CGL2017-84419 CRE; and to the Division of Entomology, University of Kansas Natural History Museum. We thank Sally Thomas and three anonymous referees for their helpful comments on an earlier draft.

\section{DATA ARCHIVING STATEMENT}

This published work and the nomenclatural acts it contains, have been registered in ZooBank: http://zoobank.org/References/D38B891F4713-4FC9-8B42-EBF4578BB291

Editor. Andrew Smith

\section{REFERENCES}

AZAR, D. 2007. Preservation and accumulation of biological inclusions in Lebanese amber and their significance. Comptes Rendus Palevol, 6, 151-156.

— and NEL, A. 2013. A new beaded lacewing from a new Lower Cretaceous amber outcrop in Lebanon (Neuroptera: Berothidae). 111-130. In AZAR, D., ENGEL, M. S., JARZEMBOWSKI, E., KROGMANN, L. and SANTIAGO-BLAY, J. (eds). Insect evolution in an amberiferous and stone alphabet. Brill, Leiden.

— PERRICHOT, V., NÉRAUdeAU, D. and NEL, A. 2003. New psychodid flies from the Cretaceous ambers of Lebanon and France, with a discussion about Eophlebotomus connectens Cockerell, 1920 (Diptera, Psychodidae). Annals of the Entomological Society of America, 96, 117-126.

_ GÈZE, R. and ACRA, F. 2010. Lebanese amber. 271-298. In PENNEY, D. (ed.) Biodiversity of fossils in amber from the major world deposits. Siri Scientific Press, Manchester. 
BACH DE ROCA, C. and GAJU-RICART, M. 1987. A study of the post-embronic development of Promesomachilis hispanica Silvestri, 1923 (Apterygota, Microcoryphia). 611618. In Proceedings of the 9th International Colloquium on soil Zoology. Nauka Press, Moscow.

— and STURM, H. 1988. Description of the male Hypomachiloides texanus Silvestri, 1911 (Microcoryphia: Meinertellidae). Entomologica Scandinavica, 19, 193-198.

BECHLY, G. and STOCKAR, R. 2011. The first Mesozoic record of the extinct apterygote insect genus Dasyleptus (Insecta: Archaeognatha: Monura: Dasyleptidae) from the Triassic of Monte San Giorgio (Switzerland). Palaeodiversity, 4, 23-37.

BENNER, J. S., KNECHT, R. J. and ENGEL, M. S. 2015. Tonganoxichnus: a revision of the ichnogenus with new material from Massachusetts. 31-43. In McILROY, D. (ed.) Ichnology: papers from ICHNIA III. Geological Association of Canada, Miscellaneous Publication, 9.

BITSCH, J. 1994. The morphological groundplan of Hexapoda: critical review of recent concepts. Annales de la Société Entomologique de France, 30, 103-129.

- and NEL, A. 1999. Morphology and classification of the extinct Archaeognatha and related taxa (Hexapoda). Annales de la Société Entomologique de France, 35, 17-29.

BÖRNER, C. 1904. Zur Systematik der Hexapoden. Zoologischer Anzeiger, 27, 511-533.

CHATZIMANOLIS, S., NEWTON, A. F., SORIANO, C. and ENGEL, M. S. 2013. Remarkable stasis in a phloeocharine rove beetle from the Late Cretaceous of New Jersey (Coleoptera, Staphylinidae). Journal of Paleontology, 87, 177-182.

COGNATO, A. I. and GRIMALDI, D. A. 2009. 100 million years of morphological conservatism in a bark beetle (Coleoptera: Curculionidae: Scolytinae). Systematic Entomology, 34, 93-100.

DElClòs, X., PEÑAlver, E., ARILlO, A., ENGEL, M. S., NEL, A., AZAR, D. and ROSS, A. 2016. New mantises (Insecta: Mantodea) in Cretaceous ambers from Lebanon, Spain, and Myanmar. Cretaceous Research, 60, 91-108.

ENGEL, M. S. 2009. A new Lower Permian bristletail from the Wellington Formation in Kansas (Archaeognatha: Dasyleptidae). Transactions of the Kansas Academy of Science, 112, 40-44.

- 2015. Insect evolution. Current Biology, 25, R845-R875.

— and GRIMALDI, D. A. 2002. The first Mesozoic Zoraptera (Insecta). American Museum Novitates, 3362, 1-20.

- 2004. New light shed on the oldest insect. Nature, 427, 627-630.

— DAVIS, S. R. and PROKOP, J. 2013. Insect wings: the evolutionary developmental origins of Nature's first flyers. 269-298. In MINELLI, A., BOXSHALL, G. and FUSCO, G. (eds). Arthropod biology and evolution: molecules, development, morphology. Springer Verlag, Berlin.

- BREITKREUZ, L. C. V., CAI, C., AlvarADO, M., AZAR, D. and HUANG, D. 2016. The first Mesozoic microwhip scorpion (Palpigradi): a new genus and species in mid-Cretaceous amber from Myanmar. The Science of Nature, $103,19$.

FRÖHLICH, A. and LU, Z. 2013. Built to break: the antenna of a primitive insect, Petrobius brevistylis (Archaeognatha). Arthropod Structure \& Development, 42, 95-106.
GADEAU DE KERVILLE, H. 1893 [1894]. Note sur les Thysanoures fossiles du genre Machilis et description d'une espèce nouvelle du succin (Machilis succini G. de K.). Annales de la Société Entomologique de France, 62, 463-466.

GRANIER, B., AZAR, D., MAKSOUD, S., GÈZE, R. and HABCHI, R. 2015. New fossiliferous sites with Barremian Charophyta in the "Grès du Liban" auct. (Lebanon), with a critical perspective regarding the nature of Munieria Deecke, 1883. Carnets de Géologie, 15, 199-229.

GRIMALDI, D. 2001. Insect evolutionary history from Handlirsch to Hennig, and beyond. Journal of Paleontology, 75, $1152-1160$.

- and ENGEL, M. S. 2005. Evolution of the insects. Cambridge University Press, Cambridge, 755 pp.

- SHEDRINSKY, A. and WAMPLER, T. P. 2000. A remarkable deposit of fossiliferous amber from the Upper Cretaceous (Turonian) of New Jersey. 1-76. In GRIMALDI, D. (ed.) Studies on fossils in amber, with particular reference to the Cretaceous of New Jersey. Backhuys Publishers, Leiden.

GRIMALDI, D. A., ENGEL, M. S. and NASCIMBENE, P. C. 2002. Fossiliferous Cretaceous amber from Myanmar (Burma): its rediscovery, biotic diversity, and paleontological significance. American Museum Novitates, 3361, 1-72.

HAMILTON, W. D. 1978. Evolution and diversity under bark. 154-175. In MOUND, L. A. and WALOFF, N. (eds). Diversity of insect faunas. Blackwell Scientific, Oxford.

HAUG, J. T., HÄDICKE, C. W., HAUG, C. and HÖRNIG, M. K. 2015. A possible hatchling of a jumping bristletail in 50 million years old amber. Neues Jahrbuch für Geologie und Paläontologie, Abhandlungen, 278, 191-199.

HENNIG, W. 1969. Die Stammesgeschichte der Insekten. Kramer, Frankfurt, 436 pp.

— 1981. Insect phylogeny. Wiley and Sons, Chichester, 514 pp.

JERAM, A. J., SELDEN, P. A. and EDWARDS, D. 1990. Land animals in the Silurian: arachnids and myriapods from Shropshire, England. Science, 250, 658-661.

KOCH, C. L. and BERENDT, G. C. 1854. Die im Bernstein befindlichen Crustaceen, Myriapoden, Arachniden und Apteren der Vorwelt. 1-124. In BERENDT, G. C. (ed.) Die im Bernstein befindlichen Organischen Reste der Vorwelt. Erster Band. II. Abtheilung. Nicolaischen Buchhandlungen, Berlin.

KUKALOVÁ-PECK, J. 1987. New Carboniferous Diplura, Monura, and Thysanura, the hexapod ground plan, and the role of thoracic side lobes in the origin of wings (Insecta). Canadian Journal of Zoology, 65, 2327-2345.

- 1991. Fossil history and the evolution of hexapod structures. 141-179. In NAUMANN, I. D. (ed.) The insects of Australia: A textbook for students and research workers 2nd edn, Vol. 1. Cornell University Press.

1997. Arthropod phylogeny and 'basal' morphological structures. 249-268. In FORTEY, R. A. and THOMAS, R. H. (eds). Arthropod relationships. Chapman \& Hall, London.

LABANDEIRA, C. C., BEALL, B. S. and HUEBER, F. M. 1988. Early insect diversification: evidence from a Lower Devonian bristletail from Québec. Science, 242, 913-916.

MAKSOUD, S., AZAR, D., GRANIER, B. and GÈZE, R. 2017. New data on the age of the Lower Cretaceous amber outcrops of Lebanon. Palaeoworld, 26, 331-338. 
GRANIER, B., AZAR, D., GÈZE, R., PAICHELER, J.-C. and MORENO-BEDMAR, J. A. 2014. Revision of "Falaise de Blanche" (Lower Cretaceous) in Lebanon, with the definition of a Jezzinian regional stage. Carnets de Géologie, 14, 401-427.

MENDES, L. F. 1990. An annotated list of generic and specific names of Machilidae (Microcoryphia, Insecta) with identification keys for the genera and geographical notes. Instituto de Investigação Científica Tropical, Estudos, Ensaios e Documentos, 155. Lisbon. 127 pp.

— 1997a. On a new fossil Microcoryphia (Insecta: Apterygota) from South-American copal. Boletim da Sociedade Portuguesa de Entomologia, 6, 245-251.

1997b. First contribution to the study of the Dominican amber Zygentoma (Insecta). Family Ateluridae. Pedobiologia, 41, 40-43.

- 1998. Second contribution to the study of the Dominican Republic amber Zygentoma (Insecta): family Lepismatidae. Canadian Entomologist, 130, 899-904.

- 2002. Taxonomy of Zygentoma and Microcoryphia: historical overview, present status and goals for the new millennium. Pedobiologia, 46, 225-233.

— and POINAR, G. O. JR 2004. A new fossil Nicoletiidae (Zygentoma, "Apterygota") in Dominican amber. Proceedings of the Entomological Society of Washington, 106, 102-109.

— 2008. A new fossil silverfish (Zygentoma: Insecta) in Mesozoic Burmese amber. European Journal of Soil Biology, 44, 491-494.

— and POINAR, G. JR 2013. Description of two new fossil Zygentoma from Mexico and the Dominican Republic. Soil Organisms, 85, 1-9.

— and WUNDERLICH, J. 2013. New data on thysanurans preserved in Burmese amber (Microcoryphia and Zygentoma Insecta). Soil Organisms, 85, 11-22.

- GAJU-RICART, M., MOLERO-BALTANÁS, R. and BACH DE ROCA, C. 2009. On the genera Allomachilis Silvestri, 1906, and Kuschelochilis Wygodzinsky, 1951 (Insecta: Microcoryphia). Pesquisa Agropecuária Brasileira, 44, 984-987.

OLFERS, E. W. M. VON. 1907. Die "Ur-Insecten” (Thysanura und Collembola im Bernstein). Schriften der Physikalisch-Ö konomischen Gesellschaft zu Königsberg, 48, 1-40.

PACKAUSKAS, R. J. and SHOFNER, R. M. 2010. A new species of jumping bristletails from Kansas (Microcoryphia: Meinertellidae: Hypomachiloides Silvestri, 1911). Journal of the Kansas Entomological Society, 83, 340-346.

PEÑAlVER, E. and DELCLÒS, X. 2010. Spanish Amber. 236-270. In PENNEY, D. (ed.) Biodiversity of fossils in amber from the major world deposits. Siri Scientific Press, Manchester.

RASNITSYN, A. P. 1999. Taxonomy and morphology of Dasyleptus Brongniart, 1885, with description of a new species (Insecta: Machilida: Dasyleptidae). Russian Entomological Journal, 8, 145-154.

— ARISTOV, D. S., GOROCHOV, A. V., ROWLAND, J. M. and SINITSHENKOVA, N. D. 2004. Important new insect fossils from Carrizo Arroyo and the Permo-Carboniferous faunal boundary. Bulletin of the New Mexico Museum of Natural History \& Science, 25, 215-246.
REMINGTON, C. 1954. The suprageneric classification of the order Thysanura (Insecta). Annals of the Entomological Society of America, 47, 277-286.

1955. The "Apterygota". 495-505. In KESSEL, E. L. (ed.) A century of progress in the natural sciences (1853-1953). California Academy of Sciences, San Francisco.

RIQUELME, F., MONTEJO-CRUZ, M., LUNA-CASTRO, B. and ZUÑIGA-MIJANGOS, L. 2015. Fossil jumping-bristletail from the Chiapas amber: Neomachilellus (Praeneomachilellus) ezetaelenensis sp. nov. (Microcoryphia: Meinertellidae). Neues Jahrbuch für Geologie und Paläontologie, Abhandlungen, 275, 93-106.

SÁNCHEZ-GARCÍA, A. and ENGEL, M. S. 2016a. Longterm stasis in a diverse fauna of Early Cretaceous springtails (Collembola: Symphypleona). Journal of Systematic Palaeontology, 15, 513-537.

— 2016b. Springtails from the Early Cretaceous amber of Spain (Collembola: Entomobryomorpha), with an annotated checklist of fossil Collembola. American Museum Novitates, 3862, 1-47.

SHAROV, A. 1948. Triassic Thysanura from the Ural forelands. Doklady Akademii Nauk, SSSR, 61, 517-519. [In Russian]

— 1957. Distinctive Paleozoic wingless insects of a new order Monura (Insecta, Apterygota). Doklady Akademii Nauk, SSSR, 115, 795-798. [In Russian]

SHEAR, W. A., BONAMO, P. M., GRIERSON, J. D., ROlfE, W. D., SMITH, E. L. and NORTON, R. A. 1984. Early land animals in North America: evidence from Devonian age arthropods from Gilboa, New York. Science, 224, 492-494.

SILVESTRI, F. 1911. Contributo alla conoscenca dei Machilidae dell' America settentrionale. Bolletino del Laboratorio di Zoologia Generale e Agraria Della Facoltà Agraria in Portici, 5, 324-350.

— 1912. Die Thysanuren des baltischen Bernsteins. Schriften der Physikalisch-Ökonomischen Gesellschaft zu Königsberg, 53, 42-66.

SINITSHENKOVA, N. D. 2000. A review of Triassic mayflies, with description of new species from western Siberia and Ukraine (Ephemerida $=$ Ephemeroptera). Paleontological Journal, 34, S275-S283.

STURM, H. and BACH DE ROCA, C. 1988. Archaeognatha (Insecta) from the Krakatau Islands and the Sunda Strait area, Indonesia. Memoirs of the Museum of Victoria, 49, 367-383.

__ 1992. New American Meinertellidae (Archaeognatha, Machiloidea). Pan-Pacific Entomologist, 68, 174-191.

_ 1993. On the systematics of the Archaeognatha (Insecta). Entomologia Generalis, 18, 55-90.

— and MACHIDA, R. 2001. Archaeognatha. 1-213. In KRISTENSEN, N. P. and BEUTEL, R. G. (eds). Handbuch der Zoologie, Band IV, Arthropoda: Insecta, Teilband 37. Walter de Gruyter, Berlin.

— and MENDES, L. F. 1998. Two new species of Nicoletiidae (Zygentoma, "Apterygota", Insecta) in Dominican amber. American Museum Novitates, 3226, 1-11.

_ and POINAR, G. O. JR 1997. A new Neomachilellus species from Miocene amber of the Dominican Republic and its 
phylogenetic relationships (Archaeognatha: Meinertellidae). Entomologia Generalis, 22, 157-170.

1998. Cretaceomachilis libanensis, the oldest known bristle-tail of the family Meinertellidae (Machiloidea, Archaeognatha, Insecta) from the Lebanese amber. Deutsche Entomologische Zeitschrift, 45, 43-48.

VERHOEFF, K. W. 1905. Über vergleichende Morphologie des Kopfes niederer Insekten mit besonderer Berücksichtigung der Dermapteren und Thysanuren, nebst biologisch-physiologischen Beiträgen. Nova Acta Academiae Caesareae LeopoldinoCarolinae Germanicae Naturae Curiosorum [Abhandlungen der
Kaiserlichen Leopoldinisch- Carolinischen Deutschen Akademie der Naturforscher], 84, 1-126.

1910. Dber felsenspringer, Machiloidea IV. systematik und orthomorphose. Zoologischer Anzeiger, 36, 425-438.

WYGODZINSKY, P. 1971. A note on a fossil machilid (Microcoryphia) from the amber of Chiapas, Mexico. University of California Publications in Entomology, 63, 101-102.

ZHANG, W., LI, H., SHIH, C., ZHANG, A. and REN, D. 2018. Phylogenetic analyses with four new Cretaceous bristletails reveal inter-relationships of Archaeognatha and Gondwana origin of Meinertellidae. Cladistics, 34, 384-406. 